OPEN ACCESS

Edited by:

Ahmed Gomaa,

National Research Centre, Egypt

Reviewed by:

Bin Duan,

University of Nebraska Medical

Center, United States

Jose Luis Arias,

University of Chile, Chile

Magda Soliman Mohamed,

National Research Centre, Egypt

*Correspondence:

Matej Baláž

balazm@saske.sk

Specialty section:

This article was submitted to

Biomaterials,

a section of the journal Frontiers in Bioengineering and

Biotechnology

Received: 30 September 2020 Accepted: 14 December 2020

Published: 27 January 2021

Citation:

Baláž M, Boldyreva EV, Rybin D,

Pavlović S, Rodríguez-Padrón $D$,

Mudrinić $T$ and Luque $R$ (2021) State-of-the-Art of Eggshell Waste in

Materials Science: Recent Advances

in Catalysis, Pharmaceutical Applications, and Mechanochemistry.

Front. Bioeng. Biotechnol. 8:612567.

doi: 10.3389/fbioe.2020.612567

\section{State-of-the-Art of Eggshell Waste in Materials Science: Recent Advances in Catalysis, Pharmaceutical Applications, and Mechanochemistry}

\author{
Matej Baláž ${ }^{1 *}$, Elena V. Boldyreva ${ }^{2,3}$, Dmitry Rybin ${ }^{4,5}$, Stefan Pavlović ${ }^{6}$, \\ Daily Rodríguez-Padrón ${ }^{7}$, Tihana Mudrinić ${ }^{6}$ and Rafael Luque ${ }^{7}$
}

${ }^{1}$ Department of Mechanochemistry, Institute of Geotechnics, Slovak Academy of Sciences, Košice, Slovakia, ${ }^{2}$ Department of Solid State Chemistry, Novosibirsk State University, Novosibirsk, Russia, ${ }^{3}$ Boreskov Institute of Catalysis, the Siberian Branch of the Russian Academy of Sciences, Novosibirsk, Russia, ${ }^{4}$ Udmurt Federal Research Centre of the Ural Branch of the Russian Academy of Sciences, Izhevsk, Russia, ${ }^{5}$ Mezomax Inc., San Francisco, CA, United States, ${ }^{6}$ Department of Catalysis and Chemical Engineering, University of Belgrade - Institute of Chemistry, Technology and Metallurgy - National Institute of the Republic of Serbia, Belgrade, Serbia, ${ }^{7}$ Department of Organic Chemistry, University of Cordoba, Cordoba, Spain

Eggshell waste is among the most abundant waste materials coming from food processing technologies. Despite the unique properties that both its components (eggshell, ES, and eggshell membrane, ESM) possess, it is very often discarded without further use. This review article aims to summarize the recent reports utilizing eggshell waste for very diverse purposes, stressing the need to use a mechanochemical approach to broaden its applications. The most studied field with regards to the potential use of eggshell waste is catalysis. Upon proper treatment, it can be used for turning waste oils into biodiesel and moreover, the catalytic effect of eggshell-based material in organic synthesis is also very beneficial. In inorganic chemistry, the eggshell membrane is very often used as a templating agent for nanoparticles production. Such composites are suitable for application in photocatalysis. These bionanocomposites are also capable of heavy metal ions reduction and can be also used for the ozonation process. The eggshell and its membrane are applicable in electrochemistry as well. Due to the high protein content and the presence of functional groups on the surface, ESM can be easily converted to a high-performance electrode material. Finally, both ES and ESM are suitable for medical applications, as the former can be used as an inexpensive $\mathrm{Ca}^{2+}$ source for the development of medications, particles for drug delivery, organic matrix/mineral nanocomposites as potential tissue scaffolds, food supplements and the latter for the treatment of joint diseases, in reparative medicine and vascular graft producing. For the majority of the above-mentioned applications, the pretreatment of the eggshell waste is necessary. Among other options, the mechanochemical pretreatment has found an inevitable place. Since the publication of the last review paper devoted to the mechanochemical treatment of eggshell waste, a few new works have appeared, which are reviewed here to underline the sustainable character of the proposed methodology. 
The mechanochemical treatment of eggshell is capable of producing the nanoscale material which can be further used for bioceramics synthesis, dehalogenation processes, wastewater treatment, preparation of hydrophobic filters, lithium-ion batteries, dental materials, and in the building industry as cement.

Keywords: eggshell, eggshell membrane (ESM), mechanochemistry, catalysis, electrochemistry, biomedical applications, sustainable resources, waste treatment

\section{INTRODUCTION}

Eggshell is one of the most common forms of food waste. Its production worldwide is 50,000 $\mathrm{t}$ per year (Palka, 2006). It basically consists of two parts: eggshell itself, which is mainly composed of calcium carbonate and eggshell membrane, which is a proteinous structure.

The chemical composition of eggshell has been reported many times (Nakano et al., 2003; Nys et al., 2004; Rose and Hincke, 2009). All reports agree that the main component is calcium carbonate in the form of calcite, its contribution is usually reported to be in the range of 94-97\% (Burley and Vadehra, 1989; Stadelman, 2000; Hunton, 2005). The other constituents encompass $\mathrm{Ca}_{3}\left(\mathrm{PO}_{4}\right)_{2}(1 \%), \mathrm{MgCO}_{3}(1 \%)$, and organic material (4\%) (Stadelman, 2000).

Apart from mainly inorganic ES, the eggshell membrane (ESM) is of purely organic character. It is composed of different proteins, the composition of which has been extensively discussed in the literature (Leach, 1982; Wong et al., 1984; Arias et al., 1991; Nakano et al., 2003; Zhao and Chi, 2009; Hincke et al., 2012; Kaweewong et al., 2013). The reported content of individual amino acids in eggshell membrane also varies in different literature sources. According to Nakano et al. (2003), the most abundant amino acids are proline, glutamic acid, and glycine.

The morphology of eggshell has been nicely described in Rodriguez-Navarro et al. (2007) and Zhou et al. (2010). It contains mainly calcite crystals, which are arranged into surface, palisade, and mammillary layers with different morphology and porosity. The eggshell membrane is a fibrous structure and the fibers are known to decrease in the diameter from outside of the egg to the inside (Zhou et al., 2010). They are also known to possess core-mantle structure, which differs in chemical composition (Li et al., 2011). The eggshell membrane can be subdivided into more structures- outer membrane, inner membrane and limiting membrane (Hincke et al., 2000). The sublayers of the ESM slightly differ in the individual amino acid content (Nakano et al., 2003). The largest difference has been observed in the case of leucine, which is more abundant in the outer ESM.

Although this paper is materials science-oriented, at least a short note about the function of eggshell and the membranes during the development of chicken embryo needs to be mentioned. Eggshell provides a barrier against pathogens and because of its porosity, it is permeable for gas exchanges. However, after fertilization, the eggshell starts to be degraded as the calcium is used for the proper development of the chick embryo. As a result of this, the bottom part of the mammillary layer is dissolved and eggshell membrane detaches (Hincke et al., 2019). This can be nicely seen from Figure 1, where the comparison of the morphology of ES/ESM of a fertilized and unfertilized egg is provided.

There are many review papers devoted to the eggshell waste showing their wide application potential in materials science (King'ori, 2011; Marwaha et al., 2018; da Silveira Pinto and de Souza, 2019; Konwar et al., 2019; Waheed et al., 2019, 2020; Girelli et al., 2020; Hamada et al., 2020; Hart, 2020). The use of eggshell waste as a food supplement (Waheed et al., 2019), for organic synthesis (da Silveira Pinto and de Souza, 2019), catalysis (Tan et al., 2015a; Laca et al., 2017), and adsorption (Carvalho et al., 2011; Guru and Dash, 2014; He et al., 2016) has been already reviewed in the past. Some technologies applying eggshell are patented (Balassa, 1971; Dawson, 2003; Cordeiro and Hincke, 2011; Schmidt et al., 2017; Kenny et al., 2018; Blaine and Thang, 2019; Huang et al., 2020). The proteinous eggshell membrane also has a great potential to be applied in materials science (Baláž, 2014), and its soluble form is applicable for tissue engineering (Sah and Rath, 2016). This contribution aims to shed a light on recent achievements in using eggshell waste in the field of materials science, namely targeting the fields of catalysis, electrochemistry, and medical applications. In the last part, an update on the recent publications utilizing mechanochemical approach for the treatment of eggshell waste is provided.

\section{EGGSHELL IN CATALYSIS}

Due to the remarkable importance of bioactive compounds for the chemical, pharmaceutical, cosmetic, and food industries, finding environmentally friendly synthetic strategies involving catalytic steps represents a key task for a sustainable development. In this regard, several factors need to be considered, including not only the green character of the catalytic materials but also the environmental benefits and the cost and energy efficiencies of the synthetic methodology for catalysts preparation. Biomass transformation toward advanced nanocatalytic systems has been demonstrated to be a very valuable option, which still requires further efforts in order to achieve optimized protocols and highly versatile and appealing materials. The suitable chemical composition, structural, morphological, and textural properties of eggshell are important to promote different catalytic reactions. Depending on the desired applications field, eggshell could be treated using different methods to obtain a catalyst with well-defined properties. The eggshell treatment methods may be divided into 


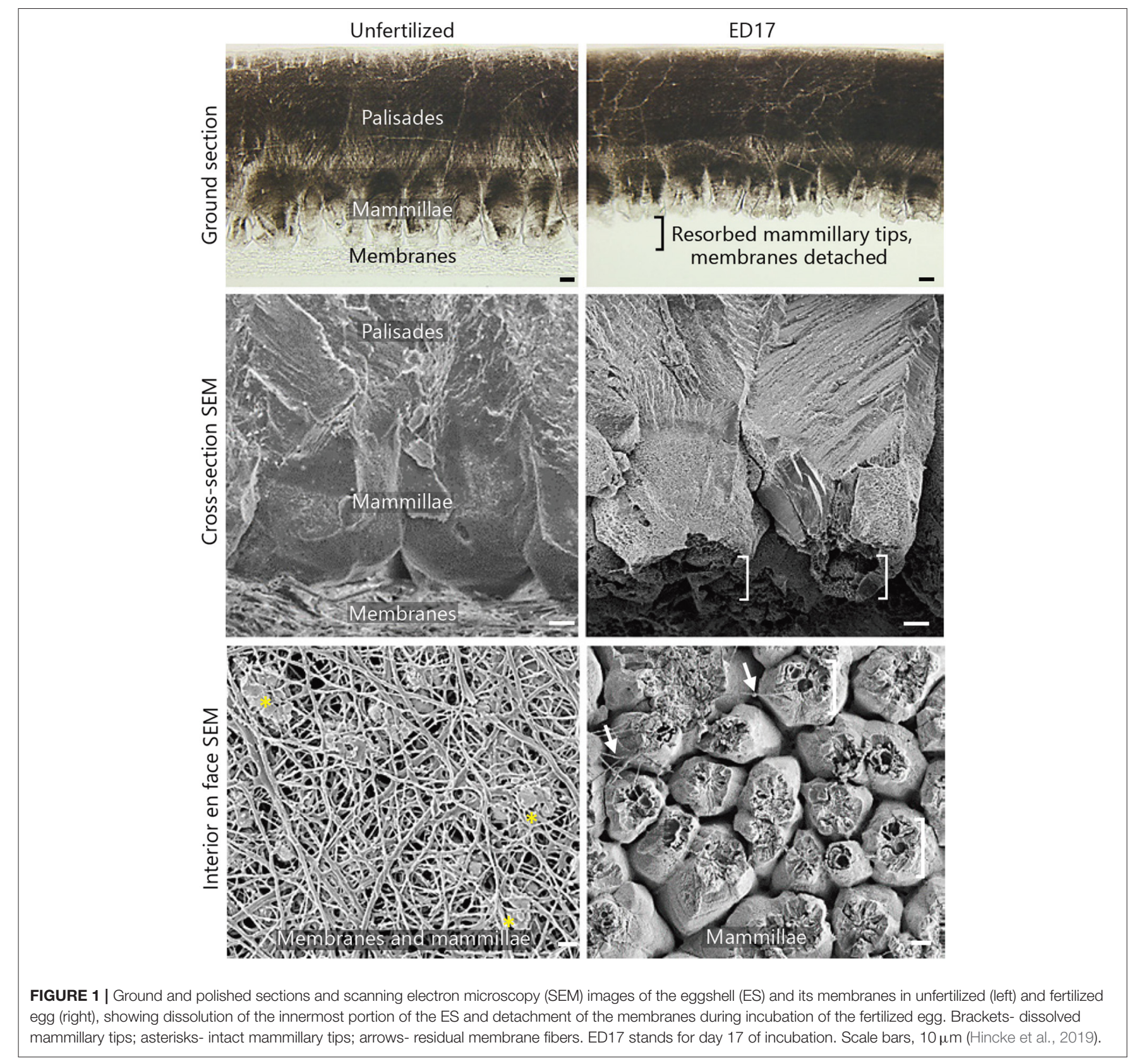

simpler ones (preceded by washing, cleaning, and drying), which include only thermal treatment (calcination in a muffle furnace in the oxygen or inert atmosphere in the temperature range 600$1,000^{\circ} \mathrm{C}$ ) or more complex methods, which include chemical reaction, hydration, dehydration, precipitation, co-precipitation, deposition, sol-gel, and interaction between two components (one of which is mainly catalytic support). In order to avoid some toxic salt solutions and save energy, there are some waste-free and low-energy demanding techniques for catalyst synthesis, such as mechanochemical one. It will be shown below that the attention of many researchers is focused on the utilization of eggshell in different environmentally beneficial processes.

\section{Synthesis of Bioactive Compounds and the Eggshell-Based Catalysis in Organic Synthesis}

Eggshell-derived nanocatalysts have been reported for the synthesis of various bioactive compounds, such as chromenones, pyran derivatives, polyhydroquinolines, aromatic aldehydes, benzothiazoles, and carbohydrates (Laca et al., 2017).

$N$-heterocycles, such as nitrogen-containing phthalazine compounds, could have potential applications as antimicrobial, antioxidant, and anti-convulsant agents. The synthesis of this family of compounds is achieved through a multicomponent reaction employing heterogeneous catalytic systems. For 
instance, the use of eggshell powder as a catalytic material for the synthesis of pyrazolo-phthalazine derivatives via fourcomponent condensation through a Knoevenagel-Michael reaction has been reported. Remarkably, the aforementioned reaction was performed in water, as a green solvent, and under moderate conditions, in terms of temperature and reaction time. Under the aforementioned parameters, eggshell powder exhibited good catalytic performance, achieving 93-98\% yield of the desired products. More importantly, as one of the most valuable possibilities that heterogeneous catalysis offers, recyclability of the material was carried out for four cycles without a considerable loss of activity (Kerru et al., 2020). Moreover, spiro-heterocycles, due to their biological activity, could also be employed for a wide range of applications as analgetic, fungicidal, and antibacterial agents. Such kind of heterocycles have been prepared by a three-component reaction, passing as well through a Knoevenagel condensation and a Michael addition, which require a catalytic system. In this sense, milled eggshell has served as an active catalyst, displaying both good catalytic activity and stability over five reaction cycles (Youseftabar-Miri, 2019). Milled and calcined eggshell residues have been also used for Knoevenagel condensation of aromatic aldehydes, which could give rise to a myriad of organic compounds with pharmacological features, such as benzylidenepropanedinitrile (Patil et al., 2013). Similar eggshell-based materials have been demonstrated to be potential candidates as catalytic materials for benzothiazoles preparation. These molecules are important bioactive scaffolds with antitumor, antiallergic, antidiabetic, and antimicrobial agents (Borhade et al., 2016).

In the aforementioned cases, the catalysts were prepared by simply milling, usually using a mortar and pestle, which certainly are one of the least expensive tools in mechanochemistry. However, the use of such instruments possesses several disadvantages, since it is not possible to precisely control milling conditions and therefore material reproducibility is compromised. Looking forward to overcoming these issues, several reports in the literature have considered the use of ball milling for the preparation of similar materials. In this sense, the ball milling assisted synthesis of nano- $\mathrm{CaO}$ derived from eggshell residues for the solventless preparation of pyrano[4,3-b]pyran derivatives has been reported. Such a catalyst-design strategy has a strong sustainable character, since it combines the use of a readily available waste, as $\mathrm{CaO}$ precursor, with the employment of a solvent-free preparation procedure. This study also considered the effect of the mechanochemical approach in the $\mathrm{CaO}$ particle size and consequently in the catalytic performance, revealing that longer milling times resulted in smaller catalyst particle size and higher product yield (Mosaddegh and Hassankhani, 2014). Mechanochemical methods have also been employed for the preparation of nano-bio calcite $\left(\mathrm{CaCO}_{3}\right)$, employing eggshell as a green source. Such material has demonstrated to be an efficient catalytic system, in terms of activity and reusability, for the solvent-free synthesis of pyrano[4,3-b]pyrans at $120^{\circ} \mathrm{C}$. Outstandingly, the eggshell derived material displayed higher surface area and improved catalytic results, in comparison with the commercially available $\mathrm{CaCO}_{3}$, validating the catalyst design and the efficient use of eggshell as $\mathrm{CaCO}_{3}$ precursor for organic synthesis applications (Mosaddegh et al., 2013).

Besides mechanochemistry, also other methodologies have been employed for the synthesis of eggshell derived materials, including ultrasound treatment and impregnation approaches. For instance, nano-eggshell powder has been prepared through an ultrasound-assisted procedure in a $\mathrm{CH}_{2} \mathrm{Cl}_{2}$ solution. The catalytic behavior of the obtained sample was evaluated in the thermal-assisted solventless condensation reaction of $\alpha$ - or $\beta$-phathol, malononitrile, and aromatic aldehydes, to obtain 2-aminochromenes, showing high product yields in short reaction times. 2-aminochromenes possess a wide range of applications due to their antioxidant, antiviral, antitubulin, antidepressant, and antihypertensive activities, among others. The sonochemically prepared nano-eggshell powder exhibited enhanced catalytic performance in comparison with the ultrasound-treated $\mathrm{CaCO}_{3}$ (Mosaddegh, 2013).

Eggshell as a catalyst for base-catalyzed reactions can be also applied for the production of important industrial chemicals, such as dimethyl-carbonate, oximes, and glycerol oligomers. In order to avoid some toxic chemicals, such as dimethylsulfate and methylhalides in methylation reactions and phosgene in polycarbonate and isocyanate synthesis, dimethylcarbonate presents a suitable chemical that meets many aspects of sustainable and green chemistry (Sankar et al., 2010). In Gao and Xu's (2012) study, the successful dimethylcarbonate synthesis was performed by the reaction between propylenecarbonate and methanol in the presence of calcined eggshell as a catalyst. In this reaction, the catalyst exhibited high activity (achieved yield was $75 \%$ ) and suitable stability (five reaction cycles). Despite the presence of impurities ( $\mathrm{Mg}$ and $\mathrm{P}$ ) in the final catalyst, the catalytic activity remained unchanged. Another group of compounds important for various organic syntheses (preparation of nitriles, amines, nitro compounds, paracetamol, oxime ethers, azatricyclic core of $( \pm)$-halichlorine, and amides), which may be obtained in the process catalyzed with eggshell, are oximes. Using eggshell-based catalyst prepared by alkali and alkalithermal treatment, oximes yield increased from 17 to 20 times (depending on the conditions of the treatment procedure), in comparison with the non-catalyzed process, respectively (Taleb et al., 2017). The suitable catalytic activity with prepared catalysts was achieved even after seven cycles, whereas the activity drop was slightly larger for alkali-thermal treated eggshell than for only alkali-treated one. The eggshell catalyst was also helpful in the reaction of glycerol-oligomers production, as its presence led to the 3,5-fold increase of reaction yield for glycerol conversion and 1.5-fold increase for oligomers yield in comparison with the non-catalyzed process (Barros et al., 2017). However, due to high calcium leaching in the reaction mixture at reaction conditions used (catalyst loading of $2 \mathrm{wt} \%$ and temperature of $220^{\circ} \mathrm{C}$ ), the catalyst exhibits low stability.

\section{Wastewater Treatment: Opportunities in Photocatalysis}

Eggshell-supported semiconductor materials have also been employed for photocatalysis, which is an area of catalysis 


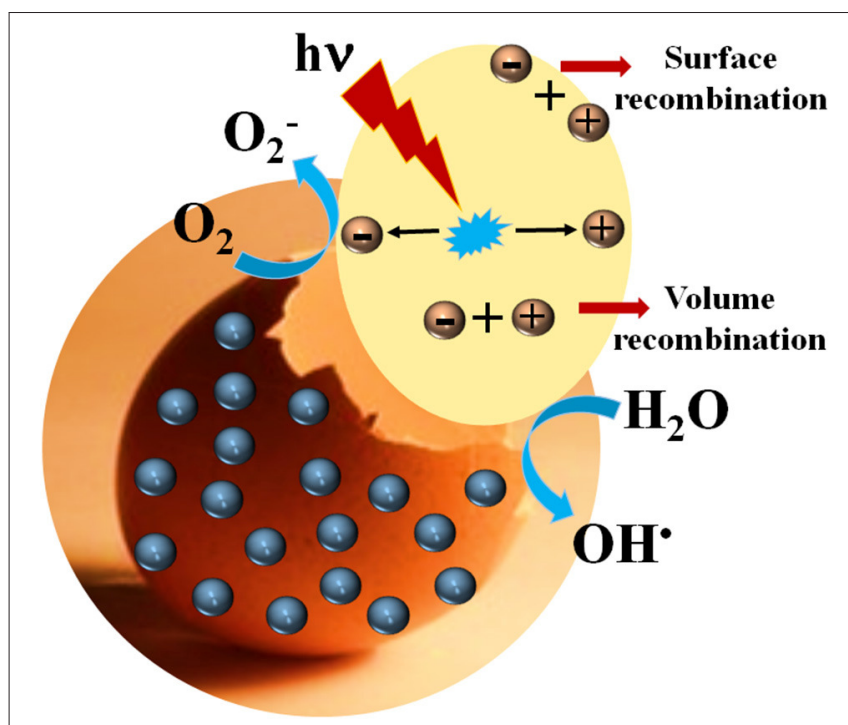

FIGURE 2 | Schematic illustration of photocatalytic processes on the eggshell-modified surface (blue spheres correspond to photocatalytically active semiconductor nanomaterials).

with an intrinsic environmentally friendly nature, where the rate of the chemical reaction is driven by the absorption of light irradiation by a semiconducting material (photocatalyst) (Rodriguez-Padron et al., 2020). Eggshell residues have been employed either as support of semiconductor materials, or as a biotemplate for the synthesis of semiconductor samples. As shown in Figure 2, the absorption of ultraviolet, visible or infrared radiation gives rise to the generation of holes and electrons, which could initiate oxidative and reductive reaction pathways, respectively (Rodriguez-Padron et al., 2019). However, surface or volume recombination phenomenon could occur, diminishing the photocatalytic activity of the samples. The efficiency of the photocatalytic process will depend on the semiconductor material. It should be also highlighted that when looking for more sustainable protocols, semiconductors able to absorb visible light are highly desirable (Munoz-Batista et al., 2018). Wastewater treatment is one of the main applications of photocatalytic processes, which could not only result in the degradation of pollutants but also in their transformation into valuable chemicals. Nowadays, the presence of dyes and organic compounds in wastewater from the pharmaceutical and textile industries constitute a major concern and an ecological challenge. For instance, the presence of dyes in wastewater could negatively affect the photosynthetic function of plants, and aquatic life by decreasing light penetration and oxygen consumption (Holkar et al., 2016).

Among the possible semiconductors that could be employed in photocatalytic applications, sulfides have risen as suitable materials for several reactions. For instance, various transitionmetal sulfides, including $\mathrm{ZnS}, \mathrm{Cu}_{2} \mathrm{~S}, \mathrm{CdS}, \mathrm{In}_{2} \mathrm{~S}_{3}, \mathrm{WS}_{2}$, and $\mathrm{MoS}_{2}$, have been reported as effective photocatalysts (Rodriguez-Padron et al., 2020). In this sense, Luque et al. have developed an efficient photocatalytic system based on copper sulfide and calcium carbonate, employing eggshell waste as a well-known source of
$\mathrm{CaCO}_{3}$ (Zhang et al., 2020b). In this work, eggshell is employed as a sustainable support, allowing the proper deposition of $\mathrm{CuS}$ nanoparticles, avoiding possible sintering effects, as indicated in the SEM-mapping analysis and facilitating the recovery and reuse of the sample. In addition, the presence of $\mathrm{CaCO}_{3}$ also resulted in the formation of reactive ${ }^{\bullet} \mathrm{CO}_{3}{ }^{-}$species, which participate in the catalytic processes. $\mathrm{CaCO}_{3} / \mathrm{CuS}$ nanocomposites were prepared by an impregnation method, after eggshell residues, used as a template, were powdered and homogenized. The obtained samples were tested in the Near-infrared (NIR) light (according to their absorption in the NIR and visible regions) induced photocatalytic degradation of 4-nitrophenol (4-NP), which is a typical water pollutant and could cause some alterations in human endocrine systems (Zhang et al., 2020b) (Figure 3A). The reduction of 4 -NP gives rise to the formation of 4 aminophenol (4-AP), which in turn is a valuable intermediate in the chemical industry, with applications in the production of valuable materials, such as analgesic and antipyretic drugs and anti-corrosion substances.

Lead sulfide is another semiconductor material, which has also been used, in combination with calcium carbonate from eggshell wastes, for solar light assisted photo-degradation of tetracycline hydrochloride (Zhang et al., 2020a). Interestingly, this work provides insights into the photocatalytic reaction mechanism of carbonate-based composite materials, where besides ${ }^{\bullet} \mathrm{O}_{2}{ }^{-}$, - $\mathrm{CO}_{3}{ }^{-}$also acts as an active species. These results could be understood considering that $\mathrm{PbS}$ excitation gives rise to electronhole pairs, and particularly the generated holes participate in the oxidation of $\mathrm{H}_{2} \mathrm{O}$ into ${ }^{\bullet} \mathrm{OH}$. Such radicals react with carbonate and bicarbonate ions to form ${ }^{\bullet} \mathrm{CO}_{3}{ }^{-}$(Zhang et al., 2020a) (Figure 3B).

Eggshell residues modified with polyethyleneimine (PEI), have also been used as support for the deposition of titania $\left(\mathrm{TiO}_{2}\right)$ nanoparticles ( $\mathrm{Li}$ et al., 2017). The modification with PEI provided amine groups on the surface of the eggshell membrane, which further favors the interactions with $\mathrm{TiO}_{2}$. The obtained material displayed good photocatalytic behavior for the degradation of pollutants, in particular Rhodamine B, which is a common dye in wastewater ( $\mathrm{Li}$ et al., 2017). In addition, $\mathrm{ZnO}$-based materials have been broadly studied for photocatalytic applications, as an alternative to titania. The similar band gap energy, together with the higher absorption efficiency under sunlight irradiation of $\mathrm{ZnO}$ (in comparison to $\mathrm{TiO}_{2}$ ) open up new possibilities for its application for visible light photocatalysis. Eggshell residues have been also used as support for $\mathrm{ZnO}$ semiconductor material. For instance, Danish et al. have reported the preparation of $\mathrm{ZnO}-\mathrm{CuO}$-supported on eggshell for photocatalytic degradation of dyes and organic compounds (Khairol et al., 2019a). The designed material displayed good results for the degradation of methylene blue, congo red, and phenol, among others, suggesting that it could be effectively used for wastewater treatment (Khairol et al., 2019a,b).

Nanocomposite materials based on $\mathrm{ZnO}$ and $\mathrm{CuO}$ employing eggshell residues as biotemplate have also been reported and tested as potential photocatalytic systems for the reduction of 4nitrophenol. Remarkably, the aforementioned pollutant could be completely degraded by using $\mathrm{CuO} / \mathrm{ZnO} /$ eggshell sample, within 8 min under light irradiation, most likely due to the efficient 


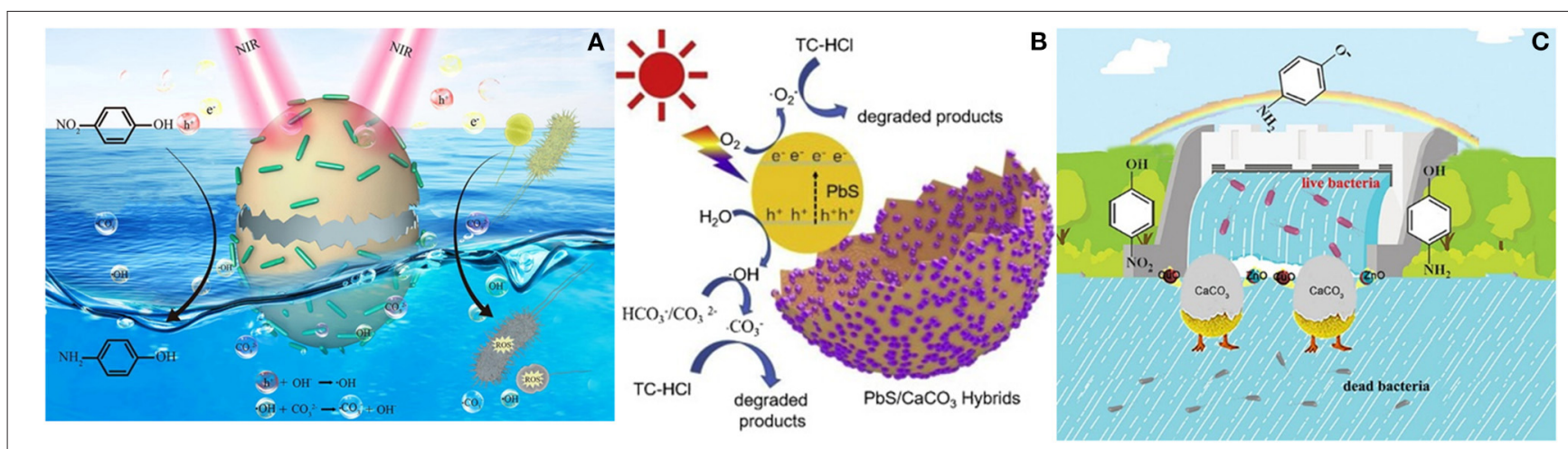

FIGURE 3 | (A) Schematic representation of 4-NP degradation using $\mathrm{CaCO}_{3} /$ CuS. Reprinted from Zhang et al. (2020b), Copyright (2020) American Chemical Society; (B) Illustrative degradation of TC-HCl over $\mathrm{PbS} \mathrm{CaCO}_{3}$ catalyst. Reprinted from Zhang et al. (2020a), Copyright (2020), with permission from Elsevier; (C) Schematic representation of 4-NP degradation using CuO/ZnO/eggshell. Reprinted by permission from Springer Nature Customer Service Centre GmbH: Springer Nature (Zhang et al., 2019a), Copyright (2019).

charge separation and the good absorbance features. Moreover, the catalyst exhibited a good stability over 5 reaction cycles, demonstrating to be a sustainable and effective candidate for photocatalytic degradation of pollutants (Zhang et al., 2019a) (Figure 3C). Besides their application for 4-NP reduction, similar materials have been also used for the photocatalytic degradation of methyl orange, achieving excellent results (He et al., 2019).

Furthermore, Yassein et al. have investigated the reduction of 4-NP toward 4-AP using $\mathrm{CuO}$-eggshell nanocomposites (Sajadi et al., 2018). In this case, the effect of $\mathrm{NaBH}_{4}$ in the reaction media was also studied, indicating that the reaction proceeds with the absorption of 4-NP and hydrogen over the metal surfaces, electron transfer from $\mathrm{BH}_{4}^{-}$to 4 -NP through $\mathrm{CuO}$ and final desorption of 4-AP. More importantly, CuOeggshell nanocomposites displayed better catalytic performance in comparison with pure copper oxide, also indicating a synergistic effect between $\mathrm{CuO}$ nanoparticles and eggshell component (Sajadi et al., 2018).

Moreover, calcium oxide nanoparticles derived from eggshell residues have also been employed as a catalytic material for the degradation of dyes, including methylene blue and toluidine blue. In this regard, Rajasekaran et al. performed a parametric analysis, considering several factors affecting the degradation rate such as catalysts loading, dye concentration and $\mathrm{pH}$ (Vanthana Sree et al., 2020). The kinetics of dye degradation over eggshell derived $\mathrm{CaO}$ material was also investigated in this work, revealing that the reaction followed a pseudo-first order. In addition, the scavenging analysis was performed for methylene blue degradation, indicating that ${ }^{\bullet} \mathrm{O}_{2}^{-}$are the primary active species in the aforementioned photocatalytic process. The eggshellderived material exhibited outstanding stability within seven reaction cycles, demonstrating to be an excellent candidate for wastewater treatment and dye degradation (Vanthana Sree et al., 2020). Similarly, $\mathrm{CaO}$ nanocrystals derived from eggshell residues by thermal annealing have been used for the sunlight-assisted photocatalytic degradation of indigo carmine. In this work, the authors further modified the calcium oxide material with silver nanoparticles. However, no considerable differences were observed for both materials $(\mathrm{CaO}$ nanocrystals and $\mathrm{Ag} @ \mathrm{CaO}$ composite) in the photocatalytic dye degradation. In any case, unmodified calcium oxide nanocrystals exhibited a noticeable photocatalytic activity, with percentages of dye degradation around 99\% (Alsohaimi et al., 2020).

\section{Other Environmentally Beneficial Applications in Catalysis}

Besides all the possibilities of the use in catalysis mentioned so far, eggshell-derived materials can be also applied in a conventional heterogeneous catalysis. For instance, bionanocomposites based on eggshell as a bioscaffold and noble metal (Pt, $\mathrm{Pd}$ ) nanoparticles have been synthesized and used for catalytic reduction of $\mathrm{Cr}(\mathrm{VI})$ to $\mathrm{Cr}(\mathrm{III})$ in aqueous solution, employing formic acid as a reducing agent (Figure 4). Importantly, metal nanoparticles were found to be well-dispersed and maintained good stability on the eggshell based support. It is well-known that $\mathrm{Cr}(\mathrm{VI})$ species are serious environmental pollutants, which are present in wastewater from several industries. Indeed, hexavalent chromium could have mutagenic and carcinogenic effects on human health. In turn, chromium (III) species are much less toxic and are used to form insoluble hydroxides. Therefore, the reduction of $\mathrm{Cr}(\mathrm{VI})$ into $\mathrm{Cr}(\mathrm{III})$ is a promising strategy for water remediation and this could be achieved using $\mathrm{Pt} / \mathrm{Pd}$ nanoparticles embedded on the eggshell membrane (Liang et al., 2014).

Eggshell-derived materials functionalized with copper and iron oxide at different concentrations have been also designed for the application in the catalytic wet oxidation of humic acid (a refractory compound present in industrial wastewaters) (Oulego et al., 2020). In this work, it was found that copper-modified eggshell showed enhanced catalytic activity in comparison with unmodified eggshell, most likely due to the better metal distribution on the eggshell support. Interestingly, eggshell by itself could also be employed to degrade humic acid and, even if less effectively, this option should be considered for future works due to the cost-efficiency of the catalyst design (Oulego et al., 2020). In another example, Asgari and coworkers have reported the preparation of carbon-doped magnesium oxide on eggshell powder as an efficient catalyst for the ozonation process to treat real wastewater from the textile industry, displaying 
improved results in comparison with commercially available activated carbon (Asgari et al., 2019).

In summary, eggshell-derived samples have a broad range of opportunities in catalytic and photocatalytic processes for wastewater treatments. Such materials include calcium oxide, calcium carbonate or even eggshell without exhaustive treatments. In particular, for photocatalytic reactions employing calcium carbonate, it has been demonstrated that ${ }^{\circ} \mathrm{CO}_{3}{ }^{-}$species also participate in the reaction mechanism. The eggshell-based catalysts could act either as efficient support or active species. Eggshell residues certainly represent an outstanding alternative with unlimited opportunities to materials traditionally applied in catalysis.

\section{Eggshell as a Biodiesel Synthesis Catalyst} The Importance of Pretreatment

It is evident that calcium oxide represents a promising catalyst for biodiesel production due to many advantages (high catalytic activity, low solubility in methanol, non-toxicity, low price, availability in nature, and being a waste material) (Marinkovic et al., 2016; Marwaha et al., 2018). In the case of eggshell utilization to obtain active catalysts, the starting material was mainly thermally treated. Namely, in the synthesis process, the pre-treatment stage is very important due to the fact that eggshell waste contains different impurities, such as the eggshell membrane, which must be removed before the calcination process. The eggshell membrane can be partially carbonized during the calcination process, whereby the obtained carbon can strongly influence the development of the porous network system inappropriate for large organic molecules, such as triacylglycerols. The calcination process is carried out mainly in the muffle furnace in the temperature range between 850 and $950^{\circ} \mathrm{C}$ in different atmospheres $\left(\mathrm{N}_{2}\right.$ and $\mathrm{O}_{2}$ both static and flow) (Salaudeen et al., 2018; Lima and Perez-Lopez, 2020), where a complete conversion of carbonate into oxide form can be achieved. Calcination conditions affect the textural properties, especially the specific surface area. In (Lima and Perez-Lopez, 2020), it was shown that the low specific surface area of the raw eggshell $\left(1.3 \mathrm{~m}^{2} \mathrm{~g}^{-1}\right)$ was increased almost 10 times by calcination in the flow of nitrogen. The specific surface area increase (albeit about five times smaller) was also achieved using calcination in the flow of oxygen. On the other hand, calcination of eggshell in the static oxygen atmosphere did not affect the specific surface area at all. Additionally, the study (Salaudeen et al., 2018) showed that calcination in the flow of carbon-dioxide is very slow and leads to incomplete conversion (max. $21 \mathrm{wt} \%$ ) of calcium carbonate into calcium oxide due to the increase of $\mathrm{CO}_{2}$ partial pressure. Many studies showed that eggshellderived calcium oxide exhibits high catalytic activity. However, low specific surface area, a non-uniform basic active sites distribution, non-defined porous network of pure and only partly calcined calcium oxide lead to low catalytic activity. Also, only partly calcined eggshell exhibits a higher tendency to leaching into reaction mixture, whereby catalyst becomes non-stable and unusable in the next reaction cycles. In order to avoid such undesirable behavior, more complex synthesis procedure should be used. Better textural, morphological, and basic properties of calcined eggshell can be obtained by hydration-dehydration (Yoosuk et al., 2010) or impregnation of calcium oxide on a suitable support, whereby it is important that suitable interaction between active species and support is achieved.

\section{Biodiesel Production Results}

The study (Pavlovic et al., 2020) showed that pure calcined eggshell exhibits great catalytic potential in biodiesel production. The catalytic activity and stability increased especially if the calcium oxide is dispersed over catalytic support, whereby the leaching of the active species is significantly reduced. In the same study, it was shown that pure calcined eggshell exhibited almost four times higher leaching of calcium into the crude biodiesel than coal fly ash-supported chicken eggshell calcium oxide. The catalyst was stable even after five reaction cycles with a negligible drop in catalytic activity. In the case when feedstock for biodiesel production contains some waste oils with high free fatty acid content, calcium oxide-supported catalysts represent satisfactory solution due to a suitable interaction between calcium oxide, as active component and the support (Stanković et al., 2020). Particularly, the role of support becomes more dominant when it exhibits an acidic character due to the presence of acid sites. Such catalysts exhibit bifunctional behavior by simultaneously carrying out the reactions of esterification and transesterification.

The studies by Gupta and Rathod (2018) and Gollakota et al. (2019) investigated the behavior of calcium oxide-supported catalysts in biodiesel synthesis from waste cooking oil. High conversion (>93.1\%) and biodiesel yield (>96.3\%) were obtained at relatively mild reaction conditions without the need of feedstock pretreatment using two eggshell-supported catalysts (calcium diglyceroxide and pyrolysis residue). In the case of pure calcined eggshell under the same operating conditions conversion $(82.1 \%)$ and biodiesel yield $(72.3 \%)$ were lower. A significant catalytic activity of eggshell in the production of biodiesel from waste cooking oil under solar irradiation was evidenced in the research of Bharti et al. (2020). It should be noted that despite lower reaction temperature $\left(40-46^{\circ} \mathrm{C}\right)$, which is below the usual $\left(\approx 60^{\circ} \mathrm{C}\right)$, and waste feedstock used (waste cooking oil), eggshell-based catalyst exhibited relatively high conversion $(\approx 90 \%)$ in the short reaction time $(2 \mathrm{~h})$. In addition, the catalyst was stable and was successfully re-used in three reaction cycles. Calcium oxide from eggshell exhibits high catalytic potential for the biodiesel synthesis from the highly acidic feedstock, like chicken fat. However, such feedstock needs to be first esterified to adjust free fatty acid content to be lower than $4 \%$. Kirubakaran and Selvan (2018) have shown that eggshell calcined at $900^{\circ} \mathrm{C}$ was still active after five reaction cycles with the highest biodiesel yield of 85\% (Kirubakaran and Selvan, 2018).

\section{Gasification Processes}

The simpler preparation procedure was used for utilization of eggshell in biomass or coal thermal conversion, which leads to the formation of various gases (depending on biomass and coal type). It can be seen that previously mentioned pre-treatment methods and calcination are sufficient to obtain a final active catalytic form. In these reactions, selectivity is particularly important. The study by Raheem et al. (2019) investigated eggshell-catalyzed 
gasification of algal biomass. During the catalyst-free process, the undesirable reactions, such as cracking and combustion occurred, and the composition of generated gas was shifted toward $\mathrm{CO}$ and $\mathrm{CO}_{2}$ with a small quantity of $\mathrm{C}_{2} \mathrm{H}_{2}$ and $\mathrm{CH}_{4}$. On the other hand, the presence of calcined eggshell led to the production of hydrogen, the amount of which increased with an increase in catalyst loading. This can be explained by adequate $\mathrm{CO}_{2}$ sorption properties of calcium oxide. The gasification process in the presence of calcium oxide takes place in two stages (rapid chemical reaction and diffusion controlled regime) and the carbonation at the first stage is inhibited by the growth of the calcium carbonate layer (Salaudeen et al., 2018). The low particle size of calcium oxide enhances the carbonation process, due to the more accessible surface. The main by-products, which can deactivate the catalyst are tar and char. Calcium oxide's ability to absorb $\mathrm{CO}_{2}$, the benefits of which are reflected in gasification reaction and lead to a selective gas formation, was used in the steam gasification process of lowrank coal, such as the sub-bituminous one used in Fan et al. (2017). This study shows the success of using the eggshell as a catalyst, as it improves carbon dioxide conversion and yields of hydrogen and carbon monoxide in the syngas. Favorable calcium behavior in the gasification reaction is explained by Ohtsuka and Asami (1997), who stated that calcium ions first undergo the ionexchange process with carbonyl group present in coal due to their high basicity. The main role of dispersed calcium is reflected in its strong interaction with carbon, which leads to the dissociation of oxygen-containing gas and oxygen spillover with the formation of oxygen complexes as active catalytic sites responsible for successful performance the coal gasification reaction.

\section{Catalytic Oxidation}

In these processes, pure eggshell does not exhibit activity at oxidation temperature characteristic for processes with conventional catalysts. However, eggshell exhibits better catalytic support in comparison with commercial calcium carbonate and allows better interaction with active species. The recent investigations show that eggshell-based oxidation catalysts exhibit acceptable activity with a special emphasis on activity, stability, and selectivity. In the study by Li et al. (2020), the eggshell-supported $\mathrm{Co}_{3} \mathrm{O}_{4}$ catalyst for benzene oxidation has been prepared. The catalyst was synthesized by the impregnation method using Co acetate solution, and the obtained precursor was calcined at different temperatures $\left(300-500^{\circ} \mathrm{C}\right)$. This process resulted in the uniform $\mathrm{Co}_{3} \mathrm{O}_{4}$ nanoparticles distribution on the eggshell support. Comparing with benzene oxidation with pure eggshell, where oxidation was carried out at $380^{\circ} \mathrm{C}$ the oxidation with eggshell-supported $\mathrm{Co}_{3} \mathrm{O}_{4}$ catalyst could be performed at a lower temperature $\left(256^{\circ} \mathrm{C}\right)$, yielding the same result. Also, the concentration of $\mathrm{Co}_{3} \mathrm{O}_{4}$ above $16.7 \%$ did not contribute to further activity increase. By in situ FTIR analysis, it is determined that active oxygen species in the catalyst directly participate in the reaction. The prepared catalyst was stable with constant benzene conversion of $95 \%$ during $50 \mathrm{~h}$. Similar research was conducted by Guo et al. (2019) with eggshell-supported Ag catalyst. It was determined that optimal Ag concentration for this process was $19.9 \%$, whereas the necessary oxidation temperature was lower $\left(225^{\circ} \mathrm{C}\right)$ than in the case of $\mathrm{Co}_{3} \mathrm{O}_{4} /$ eggshell-catalyzed process. It is important to note that this catalyst was stable even after $200 \mathrm{~h}$ with achieved benzene conversion of $95 \%$. In the preparation methods of oxidation catalysts, it can be seen that the eggshell membrane is not removed, which is contrary to the preparation methods of other catalysts. It has been confirmed that eggshell membrane is very important in regulating the particle size and metal distribution due to strong metal-protein bonding interactions. Unlike the benzene oxidation process, pure eggshell catalyst exhibits suitable activity in oxidative coupling of methane to light olefins (Lima and Perez-Lopez, 2020). In the case of catalyst, the main role is played by specific surface area, which was controlled using different calcination conditions [e.g., the changing the calcination atmosphere $\left(\mathrm{N}_{2}\right.$ or $\left.\mathrm{O}_{2}\right)$ and its state (static or flow)]. Catalysts obtained in the flow $\mathrm{N}_{2}$ and $\mathrm{O}_{2}$ atmosphere have shown similar methane conversion (30\% at $800^{\circ} \mathrm{C}$ ), whereas the catalyst calcined in static air exhibited the lowest activity due to the low specific surface area. On the other hand, using catalysts calcined in the flow $\mathrm{N}_{2}$ or $\mathrm{O}_{2}$, equal amounts of ethane and ethylene fractions were generated, which is not case for the catalyst obtained by calcination in static air (more selective toward ethane than ethylene). At a high reaction temperature $\left(800^{\circ} \mathrm{C}\right)$, the eggshell catalysts calcined in flow of $\mathrm{N}_{2} / \mathrm{O}_{2}$ (methane conversion of $25 \%$ ) and those calcined in static air atmospheres (methane conversion of 17\%) were stable for $5 \mathrm{~h}$.

These studies have demonstrated that eggshell-based catalysts outperformed other types of support materials (i.e., commercial $\mathrm{CaCO}_{3}$; Guo et al., 2019; Li et al., 2020 and oyster shell; Li et al., 2020) as well as pure NPs (Guo et al., 2019; Li et al., 2020). Moreover, Guo et al. showed that Pt NPs/eggshell exhibited a more preferable catalytic activity compared to that of commercial 5Pt/C catalyst (Guo et al., 2020). Authors working in this field claim that the enhanced catalytic activity of eggshell-based catalysts is driven by the comprehensive effect of chemical composition and morphology of the eggshell. More specifically, functional groups present on the surface of the eggshell provide a high dispersion of NPs on eggshell supports through the strong metal-functional groups bounding interaction and consequently improved catalytic performances. The strong interaction between NPs and eggshell causes the decomposition of the eggshell (i.e., $\mathrm{CaCO}_{3}$ ) to take place at a lower temperature compared to that of the pure eggshell, which has a positive impact on catalytic performance. The hierarchical porous structure of eggshell also significantly contributes to the enhancement of overall catalytic performance as it increases the contact area between VOCs and NPs and enhances mass and energy transfer. Finally, it is worth mentioning that the fine-tuning of catalytic performance [i.e., turnover frequencies and the temperature for achieving $90 \%$ benzene conversion $\left(\mathrm{T}_{90 \%}\right)$ ] of eggshell-based catalysts can be easily accomplished by the appropriate choice of parameters such as type of metal, metal loading, method of synthesis, calcination atmosphere, and temperature (Guo et al., 2019, 2020; Li et al., 2020).

\section{Limitations}

Despite many advantages of the eggshell (availability, nontoxicity, and low price), there are certain limitations in 


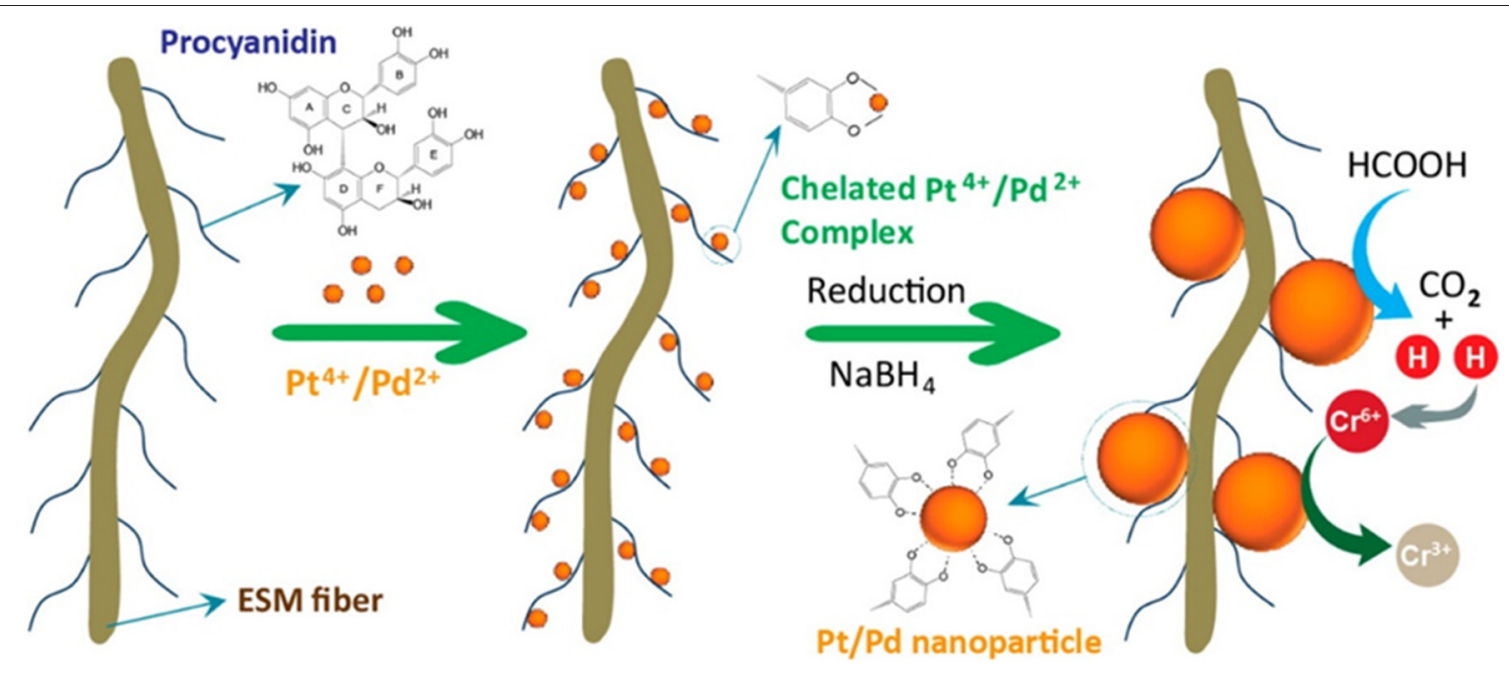

FIGURE 4 | Synthetic strategy for bionanocomposites based on eggshell and noble metal (Pt, Pd) nanoparticles and their application for Cr (IV) reduction. Reprinted from Liang et al. (2014), Copyright (2014) American Chemical Society.

terms of textural properties that complicate the process of eggshell application and manipulation. These limitations are reflected in an insufficiently developed system of pores and channels, characteristic for non-porous materials, materials with macropores or open voids, that are directly related to the active specific surface (Tan et al., 2015b). Moreover, the specific surface area is in this case correlated with the distribution of active species available for the chemical reaction, which has a direct impact on catalytic activity and hence the higher surface area catalyst is expected to have higher catalytic activity (Kumar and Ali, 2012). However, during catalyst preparation, it is important to conduct a controlled synthesis in order to obtain an optimal specific surface area with a well-developed pores in the mesoporous region. Special attention should be drawn to the organic part of the eggshell, which can be transformed into unburned carbon, which leads to a formation of material with high specific surface area and pores in the micro-region (Manique et al., 2017). The biodiesel production is strongly influenced by intra-catalyst mass transport limitations, which are due to the slow diffusion of high molecular weight triacylglycerol molecules inside the catalyst process (Pavlovic et al., 2020). This is precisely the reason why it is important to make eggshell modification in terms of adjusting the specific surface area, and obtaining a system of available pores and channels with the adequate positioning of the active catalytic species.

\section{APPLICATION OF EGGSHELL-BASED MATERIAL IN ELECTROCHEMISTRY}

Although electrically non-conductive, ES and its membrane have been attracting great attention from electrochemists. Properties and applications of the ESM that are important from an electrochemical standpoint are summarized in a review paper (Baláž, 2014). Ever since, there have been growing numbers of papers dealing with this topic. To this end, herein we will describe recent progress concerning the utilization of both ES and ESM in the field of electrochemistry.

ESM in its unmodified form has only found its application as a separator in energy storage devices. Yu et al. demonstrated that an avian ESM separator could replace the conventional polypropylene separator in supercapacitors (Yu et al., 2012). Recently, Nguyen et al. studied eggshell membranes of various species (i.e., quail, chicken, goose) as separators in lithiumion batteries (LIB) (Nguyen et al., 2018). It was established that different surface morphology, surface area and thickness of the ESMs affected the electrochemical performances such as discharging capacity, impedance and lithium-ion diffusion coefficient of Li-ion batteries.

On the other hand, ESM can be easily modified and consequently, high-performance electrode materials can be obtained. The presence of functional groups on the surface and high protein content make ESM suitable for various types of modifications. The functional groups have two important roles for the preparation of electrode materials: one is their ability to anchor electroactive metal precursors on ESM surface and the other is to reduce the metal cations to zero-valent metal nanoparticles. For instance, Selvacumari et al. showed that ESM can be used for the synthesis of metal oxides (i.e., $\mathrm{SnO}_{2}$ ) as a supercapacitor electrode material without using any toxic chemicals (Selvakumari et al., 2018). The suggested mechanism for $\mathrm{SnO}_{2}$ synthesis includes the reduction of the adsorbed $\mathrm{Sn}^{2+}$ on $\mathrm{ESM}$ into $\mathrm{Sn}^{0}$ by an aldehydic group naturally present in ESM. Upon annealing, $\mathrm{SnO}_{2}$ nanoparticles are formed through oxidation of $\mathrm{Sn}^{0}$. Meng and Deng demonstrated that $\mathrm{NiO}$ attached to carbonized ESM can be partially reduced to $\mathrm{Ni}$ in the reducing environment provided by released reducing agents from the ESM under heating (Meng and Deng, 2019). On the other hand, due to high protein content (rich in C and N), the ESM can be easily converted to functional carbon 
and heteroatom-doped (i.e., doped with nitrogen, oxygen and sulfur) carbon by its carbonization in an inert atmosphere. This results in an enormous potential of ESM application for energy conversion and storage devices (Li et al., 2012). Recent progress has been made in the development of composite materials based on non-noble metal compounds (oxides, sulfides etc.) and carbon derived from eggshell membrane. Meng and Deng used eggshell membrane as a bio-template for the formation of both carbon fibers and functional sulfides $\left(\mathrm{Co}_{9} \mathrm{~S}_{8}\right)$ based on in situ carbonization and sulfurization (Meng and Deng, 2016). This approach paved the way for the integrated use of eggshell waste and at the same time for the synthesis of functional nanostructures. A similar procedure was applied for syntheses of $\mathrm{NiO}$ ( $\mathrm{Lu}$ et al., 2019), NiO-Ni (Meng and Deng, 2019), FeS (Zhao et al., 2019a), and $\mathrm{Co}_{4} \mathrm{~S}_{3}$ (Xie et al., 2019) attached to the carbonized eggshell membrane (CESM) as electrodes. Improved electrochemical performance of composite materials compared to those of single component was attributed to the synergetic effect of CESM and metal oxide/sulfide nanoparticles. Moreover, Tong et al. demonstrated that FeCo alloy embedded in nitrogen self-doped carbon derived from ESM composite could be a good candidate for the substitution of commercial $\mathrm{Pt} / \mathrm{C}$ (20\%) electrocatalyst for oxygen reduction reaction (ORR) (Tong et al., 2017). The authors also found that pyrolysis temperature played a crucial role in controlling crystallinity, nitrogen and carbon content and textural properties of CESM and accordingly affected the electrocatalytic activity. Cui et al. also fabricated a competitive ORR electrocatalyst based on carbon nanofibers with a hierarchical structure, prepared by combining Co-containing zeolitic imidazolate frameworks with natural ESM (Cui et al., 2020). ESM was introduced to ensure the desired porous structure and to protect the aggregation of nanoparticles. As a result, they have noted the enhancement of mass transfer efficiency and consequently, electrocatalytic performance.

Recently, the research group of Pequendo de Olivera has recognized that eggshell membrane could be used for designing electrodes suitable for contemporary flexible supercapacitors (SCs) based on carbon nanostructures (CNs) material and conducting polymers (Alcaraz-Espinoza et al., 2017; da Silva et al., 2020). Fabrication of the supercapacitor electrodes often requires using binder materials or surfactants that could derogate electrochemical performance. On the contrary, authors suggested that flexible supercapacitor (SC) can be designed without the addition of auxiliary substances by the electrostatic assembly of CNs on pristine ESM (owing to the presence of functional groups), which was succeeded by the in situ polymerization of conducting polymer.

Utilization of ES has recently emerged in energy storage devices. Minakshi et al. have introduced the pioneering concept of using $\mathrm{CaCO}_{3}$ from eggshell as the cathode in $\mathrm{Li}$-ion capacitors (LIC) in a non-aqueous electrolyte (Minakshi et al., 2018). Interestingly, the ES-based electrode showed a capacitance of $120 \mathrm{Fg}^{-1}$ (which was comparable to a classically activated carbon electrode under the same conditions) and good cyclic stability, with a capacity retention of $92 \%$ after 1,000 cycles. Moreover, the same group of authors concluded that eggshellderived materials are suitable for the construction of electrode materials for aqueous energy storage devices (Minakshi et al., 2019). They built a symmetrical aqueous supercapacitor using chicken eggshell $\left(\mathrm{CaCO}_{3}\right)$ as a cathode and its calcined form $(\mathrm{CaO})$ as an anode, achieving the energy density of $14.5 \mathrm{~W} \mathrm{~h}$ $\mathrm{kg}^{-1}$ and power density of $525 \mathrm{~W} \mathrm{~kg}^{-1}$. In their latest work, Minakshi et al. fabricated a hybrid device comprising eggshellderived $\mathrm{CaO}$ as a capacitor anode and $\mathrm{NiO} / \mathrm{Co}_{3} \mathrm{O}_{4}$ as a pseudocapacitor cathode with enhanced energy density up to $35=$ $\mathrm{W} \mathrm{h} \mathrm{kg}{ }^{-1}$ (Minakshi et al., 2020). Also, eggshell was utilized as an inexpensive $\mathrm{Ca}^{2+}$ (Foruzin et al., 2020) and $\mathrm{CaO}$ (Senthil et al., 2019) chemical source for the doping and coating of active electrode materials.

Recently, both ESM and ES have been investigated for electroanalytical purposes. ESM was used as a removable template for the synthesis of the $\mathrm{Au} / \mathrm{CeO}_{2} 3 \mathrm{D}$ nanocomposite network (Liu et al., 2020a) and 3D Au porous network (Zhong et al., 2017) in the fabrication of electrochemical non-enyzmatic dopamine and glucose sensors, respectively. Superior electroanalytical performances of the developed sensors were attributed to the unblocked macroporous network and interwoven fiber structure of electroactive materials that provided small hindrance of analytes and great availability to active sites. Additionally, the rigid structure of the 3D network prevents the derogation of the sensor by aggregation and consequently improves operation and storage stability. On the other hand, it was shown that due to its porous structure and active nucleation sites ES can be employed as a support for nanoparticles and can be applied in the electroanalytical determination of various analytes. For instance, $\mathrm{Au} / \mathrm{CaCO}_{3}$ was used for 4-nitrophenol electrochemical detection (Ding et al., 2020), while $\mathrm{Fe}_{3} \mathrm{O}_{4}$ /eggshell composites were applied for the voltammetric determination of cadmium (Mohammadi et al., 2019).

In another report, Zhang et al. demonstrated a new approach for the utilization of every individual component of the egg in the formation of a 2D graphene-like carbon electrode and gellike solid-state electrolyte (Zhang et al., 2019b). 2D graphene-like carbon was obtained by the carbonization of egg white/yolk at $650^{\circ} \mathrm{C}$ in argon with eggshell-derived $\mathrm{CaCO}_{3}$. Authors suggested that the $\mathrm{CO}_{2}$ released during the degradation of $\mathrm{CaCO}_{3}$ played a crucial role in the formation of $2 \mathrm{D}$ morphology with the high surface area of $593.1 \mathrm{~m}^{2} \mathrm{~g}^{-1}$. Further activation of eggderived carbon with $\mathrm{KOH}$ increased the surface area to 1,572 $\mathrm{m}^{2} \mathrm{~g}^{-1}$. By mixing egg white/yolk with $\mathrm{KOH}$, the gel-like solid electrolyte was obtained with competitive ionic conductivity and water preservation. Thereby, they introduced a concept that every part of the egg may be used for the construction of various parts of supercapacitor components. Fascinatingly, the authors constructed an all-solid flexible supercapacitor only based on the egg that exhibited the capacitance retention rate of $80 \%$ after 5,000 cycles at the current density of $1 \mathrm{~A} \mathrm{~g}^{-1}$.

\section{Limitations}

Although excellent electrochemical performances of both ES and ESM were achieved, there are still some challenges that hamper their wide use. Most research in the field of electrochemistry has been focused on converting eggshell waste into a high-value 
carbon material and its further improvements by combining it with transition metals. On the other hand, it is unclear whether ESM-derived carbon can be fabricated in a reproducible manner. For instance, a small variation in the morphology of ESM-derived carbon may cause substantial changes in its electrochemical properties. Therefore, the lack of the reproducibility could present a major hurdle for large-scale application of ESM-derived carbon in electrochemical devices.

\section{EGGSHELL IN THERAPEUTICS}

Both ES (mineral ES) and ESM (ES membrane) find various biomedical applications both as a raw natural source, and as components of synthesized materials. Numerous medical applications of ES (Rovensky et al., 2003; Baláž, 2018) and ESM (Baláž, 2014; Park et al., 2016; Sah and Rath, 2016) have been surveyed previously. Correspondingly, this review primarily discusses the advances which have been made since 2018 .

\section{Biomedical Applications of Mineral Eggshell}

ES is used as an inexpensive $\mathrm{Ca}^{2+}$ source for the development of medications (Rovensky et al., 2003; Siemiradzka et al., 2018), as particles for drug delivery (Jayasree et al., 2018; Verma et al., 2019), within organic matrix/mineral nanocomposites as potential tissue scaffolds in bone grafting (Apalangya et al., 2019; Shafiei et al., 2019; Trakoolwannachai et al., 2019; Wu et al., 2019; Ingole et al., 2020), and in food supplements (El-Shibiny et al., 2018; Islam et al., 2019; El-Zeftawy et al., 2020).

Calcium-containing medicines, food supplements, and vitamin-mineral complexes are mainly intended for the concomitant treatment of osteopenia and osteoporosis, and for the prevention of osteoporotic fractures. Osteoporosis is associated with a gradual decrease in bone mineral density (BMD) due to some imbalance in bone tissue remodeling when bone resorption, rather than bone formation prevails (Florencio-Silva et al., 2015). Bone resorption happens, for example, if the production of hormones and cytokines which trigger the process of osteogenesis subsides as a consequence of natural aging, immobilization, or from toxic effects of the environment. Resorption is initiated by osteoclasts. Within the lacunae formed by osteoclasts, osteoblasts create a new extracellular organic matrix (collagen type I), followed by a subsequent mineralization which yields precipitated crystals of the calcium-based mineral, hydroxyapatite (HA). Calcium also plays a crucial role in the transmission of intercellular and intracellular signals, and facilitates allosteric regulation in a series of biochemical reactions, thereby affecting both the differentiation and proliferation of cells, including bone-forming osteoblasts (Munaron, 2006; Blair et al., 2011). Therefore, bone resorption can be triggered by calcium-dependent PTH release and the subsequent osteoclast activation through the RANK/RANKL/OPG signaling pathway ${ }^{1}$ to compensate for the reduced concentration of calcium in the serum. So, the

${ }^{1} \mathrm{PTH}$ (parathyroid hormone). Its secretion is determined chiefly by serum ionized calcium concentration through negative feedback. PTH is secreted when $\mathrm{Ca}^{2+}$ prevailing opinion is that calcium supplements can slow down the osteoporotic degradation of bone tissue.

Calcium is not, however, without its hazards. To avoid hypercalcemia and its negative health consequences, the calcium release profile of medicines and supplements should be provided properly, maintaining optimum calcium concentration in the blood serum. In a recent study (Siemiradzka et al., 2018), tablets were produced from the mineral ES, roasted at $120^{\circ} \mathrm{C}$ for $2 \mathrm{~h}$, and sieved to unify grain size. Calcium citrate prepared using ES as raw material and calcium bis-glycinate were completely released within $150 \mathrm{~min}$. At the same time, ES calcium carbonate added to calcium bis-glycinate prolonged the release of calcium ions to $4 \mathrm{~h}$.

Evaluation of the optimum calcium release profile is also related closely to the determination of adequate dosages. Moreover, the range of effective dosages should be established for each indication. However, the biological response to the dose of administered calcium could be non-linear. The dosage dependence of ES calcium supplements on obese disorders in rats was studied for 26 weeks (El-Zeftawy et al., 2020). A low dose of ES supplement $\left(7.2 \mathrm{~g} \mathrm{Ca}^{2+}\right.$ in form of $\mathrm{ES} / \mathrm{kg}$ rat) for the treatment of rats with a high-fat diet led to significant enhancement of lipid profiles, liver enzymes, kidney functions, leptin, adiponectin, $\mathrm{Ca}^{2+}, 25$-hydroxyvitamin $\mathrm{D}$, thyroid-stimulating hormone, free thyroxine, and PTH levels. The superoxide dismutase specific activity was elevated, thereby improving the antioxidant response. However, a high dose of $\mathrm{Ca}^{2+}\left(18 \mathrm{~g} \mathrm{Ca}^{2+}\right.$ in form of ES/kg rat) and a low-fat diet were less effective for the treatment of obese rats, as compared to providing rats with a low dose of ES alongside the high-fat diet. Thus, $\mathrm{Ca}^{2+}$ supplementation by ES can be regarded as a beneficial approach for obesity management with anti-cholesterol effects in low dose treatment. There was a reduction in weight gain, body weight, body mass index, blood glucose, insulin, and homeostasis model assessment of insulin resistance.

The main message of some studies is that the additional calcium sources should be included into the diet, to normalize the process of bone remodeling, because «a typical dietary calcium intake is not sufficient to satisfy the recommended daily calcium intake for all age groups $\gg$ (El-Shibiny et al., 2018). To enhance the bioavailability of poorly soluble calcium salts, the eggshell powder is processed into the nano-sized state, which is characterized by high water absorption and lower zetapotential as compared to micro ESP (eggshell powder) (ElShibiny et al., 2018). ES was milled to achieve nano-sized particles $(\sim 10 \mathrm{~nm})$ agglomerated into clusters of few $\mu \mathrm{m}$. However, after ultrasound treatment of suspension and filtration through a $0.45 \mu \mathrm{m}$ membrane filter, rapid aggregation of nano-sized particles was observed. This aggregation was attributed to the hydrophobic nature of the crystalline particles. Yogurt from the milk of buffalo and cows was fortified with nano-ESP up to $0.3 \%$ with no adverse effects or biochemical changes in the product.

concentration is decreased. RANK (Receptor activator of nuclear factor kappaB); RANKL (Receptor activator of nuclear factor kappa-B ligand) - a membrane protein, a member of the tumor necrosis factor (TNF) cytokine family, it binds to RANK on cells of the myeloid lineage and functions as a key factor for osteoclast differentiation and activation; OPG (osteoprotegerin). 
The design of mineral composites themselves and organic matrix/mineral composites (OM/MC) as potential tissue scaffolds is another interesting application of ES. ESP or ESPderived HA are implanted into the organic matrix, to enhance its mechanical properties and thermal stability, increasing simultaneously specific surface area to provide osteoblast-like cells infiltration and better adhesion (Apalangya et al., 2019; Trakoolwannachai et al., 2019; Wu et al., 2019). Ca-based minerals seem to stimulate osteoblast differentiation and proliferation in vitro and in vivo.

In a recent review (Opris et al., 2020) and original papers (Kattimani and Lingamaneni, 2019; Kattimani et al., 2019a,b) clinical studies on the effect of nano-dispersed $\mathrm{HA}$ as a substitute material in oral surgery were described in detail. Both ESP-derived HA and synthetic HA promoted bone regeneration displaying similar healing characteristics confirmed with histological analysis and microcomputed tomography.

$\mathrm{OM} / \mathrm{MC}$ on the basis of ESP-reinforced microparticle hydrogels implanted in a rat model enabled the differentiation of pre-osteoblasts enhancing mineral deposition by these cells (Wu et al., 2019). The hydrogel porous matrix allowed the pre-osteoblast migration in $3 \mathrm{D}$ and provided integration of the ESP. Gelatin methacrylate-ESP composite did not generate inflammatory responses in vivo and integrated well with the host. More importantly, the osteogenic differentiation was induced in a concentration-dependent manner, without using a specialized osteogenic growth medium.

The shape of the particles and the associated specific surface area are important characteristics for cell viability in the process of bone grafting. A potential scaffold for tissue regeneration was described in Apalangya et al. (2019), where ESP-derived nanodispersed HA and poly(lactic) acid electrospun fibers composite (PLA/HA) was fabricated. HA particles were obtained from a pre-milled ES/ethanol/water/propylene glycol suspension using two sets of $6 \times 3 \mathrm{~mm}$ and $12 \times 6 \mathrm{~mm}$ diameter stainless-steel balls simultaneously, followed by the addition of diammonium hydrogen phosphate and ammonium hydroxide solution. The resulting elongated milled particles ranged in lengths from 100 to $120 \mathrm{~nm}$ and their diameters ranged from 10 to $20 \mathrm{~nm}$. The nanostructured HA agglomerates displayed a high specific surface area to enable a better biological activity of osteoblastic cells (Laranjeira et al., 2010). The porous OM/MC structure was suitable for cell infiltration and proper attachment.

The enhanced osteogenic activity was displayed in poly ( $\varepsilon$-caprolactone) (PCL)/polyvinyl alcohol (PVA) nanofibrous scaffolds doped by both carbon dots and ES-derived calcium phosphates in Shafiei et al. (2019). Such doping demonstrated a synergetic effect, promoting a high osteogenic differentiation and proliferation rate.

Fiber/HA nanocomposites of another type were produced by synthesizing (2,2,6,6-tetramethylpiperidin-1-yl)oxyl (TEMPO)oxidized cellulose nanofibrils (TCNFs), or cellulose nanocrystals (CNCs) with hydroxyapatite (HA) in varying composition ratios (Ingole et al., 2020). $\mathrm{Ca}(\mathrm{OH})_{2}$ obtained from eggshells and $\mathrm{NH}_{4} \mathrm{H}_{2} \mathrm{PO}_{4}$ used as $\mathrm{HA}$ precursors were mixed in a stoichiometric ratio of $\mathrm{Ca} / \mathrm{P}=1.67$. The mixture was ground in an agate mortar with a pestle, and subsequently dissolved in distilled water and heated to form a HA solution. The solution was then ultrasonicated and subjected to uniaxial compression. HA with either nanocellulose type (nanofibrils or nanocrystals) was found to improve human osteoblast cell viabilities.

Chitosan was used as a natural organic matrix (as an alternative to synthetic matrices) of a prospective scaffold (Trakoolwannachai et al., 2019). Chitosan is a biomaterial produced by alkaline deacetylation of chitin, composed of b-(14)-D-glucosamine and $\beta$-(1-4)-N-acetyl-D-glucosamine (Santos et al., 2019). Among other benefits, chitosan demonstrates antioxidant, anti-allergic, anti-inflammatory, and antimicrobial activities (Santos et al., 2019). The last one is of utmost importance, to prevent typical adverse reactions during bone grafting and wound healing. 10-30 wt.\% of hydroxyapatite was loaded into the chitosan film, binding to the hydrophilic $-\mathrm{OH}$ and $\mathrm{NH}_{2}$ and lowering the water content in the composite (Trakoolwannachai et al., 2019). To produce HA, orthophosphoric acid and ESP were co-precipitated with ammonium hydroxide, adjusting the $\mathrm{pH}$ of the solution to 10 . The reinforcement of the matrix with HA particles imposes an obstacle for chitosan chain movement, thereby increasing the glass transition temperature while the melting point stays the same. The chitosan film with an increased roughness becomes a suitable support for cell growth.

ES-derived carbonated calcium deficient nano-HA can be used both in bone substitutes and in local drug delivery systems demonstrating the improved cellular response compared to synthetic calcium-deficient hydroxyapatite nanoparticles (Jayasree et al., 2018; Verma et al., 2019). Calcium hydroxide with residual carbonate content (ES heated at $805^{\circ} \mathrm{C}$ for $1 \mathrm{~h}$ ) in distilled water suspension and diammonium hydrogen phosphate solution at $\mathrm{Ca} / \mathrm{P}$ ratio of 1.61 were mixed and $\mathrm{HA}$ synthesis was accelerated by a microwave irradiation. Carbonate $\left(\mathrm{CO}_{3}^{2-}\right)$ group substitution $\sim 6 \%$ for the phosphate $\left(\mathrm{PO}_{4}^{3-}\right)$ group in ES-derived HA reduced the crystallinity down to $4 \%$ compared to $15 \%$ in synthetic HA. The substitution suppressed crystal growth and increased the surface area and solubility. As a potential nano-carrier for the local drug delivery, ES-derived carbonated HA showed higher drug loading and releasing compared to the synthetic analog in the studies with doxycycline and curcumin.

\section{Limitations}

In summary, in vitro and in vivo studies demonstrate low toxicity and substantial efficacy of ES-derived active pharmaceutical ingredients (APIs) for bone grafting. Nevertheless, discussions concerning the efficacy of calcium-containing supplements at osteoporosis treatment and preventing fractures continue. Numerous clinical studies and metadata analyses show equivocal results when using similar compounds (Rovensky et al., 2003; Grant et al., 2005; Reid et al., 2015; Tai et al., 2015; Yao et al., 2019; Reid and Bolland, 2020). Moreover, cardiovascular and gastrointestinal adverse events, together with renal calculi in calcium supplement use were reported to be likely (Reid et al., 2015; Reid and Bolland, 2020). The deficiency in regulative hormones and cytokines modulating calcium signaling pathways, such as cholecalciferol, PTH, and BMP2, disrupt proper calcium assimilation, as well as differentiation and proliferation of osteoblasts. That is why a mere intake of calcium supplements, 


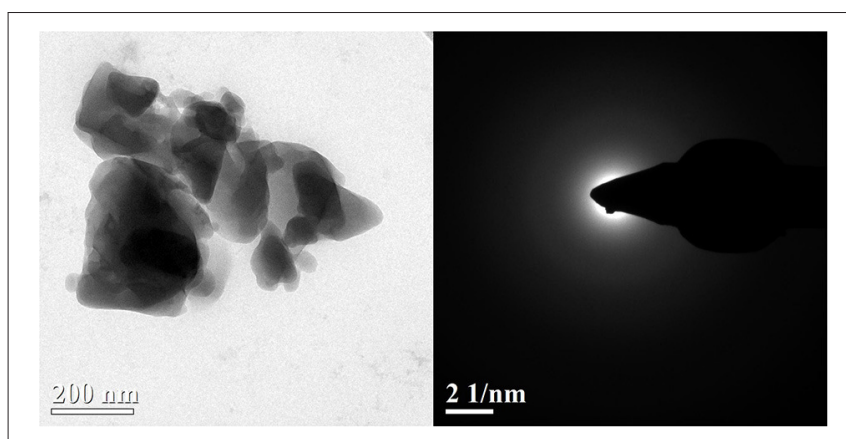

FIGURE 5 | TEM of mechanically activated calcium salt of gluconic acid. Reprinted from Rybin et al. (2018) with permission from UdmFIC UB RAS.

without normalizing calcium metabolism, does not appear to resolve issues concerning a decrease in the magnitude of BMD. Instead, taking calcium supplements in this way can yield severe side-effects. In certain cases, some discrepancies in the conclusions of the published studies could be explained by the study design. It is important to know how the experimental protocol was controlled. Therefore, it is obvious that the choice of the correct experimental model for each indication when conducting preclinical studies is a priority task. Unfortunately, when developing the design of efficacy studies of ES-derived medicines, the physical state of a substance is rarely taken properly into account. At the same time, it is well-known that a drug should be considered as a material (Gardner et al., 2004; Boldyreva, 2016). The ability to deliver the medicine to targets substantially depends on the properties of API-containing compounds in the solid state, such as polymorphism, crystal shape, size, defects, etc. (Boldyreva, 2016). A striking example is the transformation of a crystalline API into an amorphous state, that can drastically modify both the pharmacokinetic and pharmacodynamic characteristics of a drug (Rams-Baron et al., 2018). For example, mechanical treatment of a complex based on calcium gluconate converts it into a nano-dispersed amorphous state (Figure 5) (Rybin et al., 2018). As a result, the physicochemical and biological properties of the complex change radically (Konygin et al., 2014; Rybin et al., 2014), converting it into a new non-protein regulator of calcium metabolism. Another example is amorphous calcium carbonate, which plays a significant role in biomineralization (Cartwright et al., 2012). The origin of the benefits of amorphous calcium carbonate on bone grafting and osteogenesis, as compared to the crystalline compound, still needs to be explored in detail. Thus, a comparative assessment of the clinical effectiveness between APIs manufactured from eggshells and from other sources should be carried out, considering the physical properties of drugs as materials, i.e., characterizing the samples by a complete set of structural parameters on microscopic, mesoscopic, and molecular scales.

\section{Biomedical Applications of Eggshell Membrane (ESM)}

The eggshell membrane (ESM) is another important component, which is widely used for various applications, including in biomedicine, such as for the treatment of joint diseases, applications in reparative medicine (in particular, wound healing and sciatic nerve regeneration), and for producing vascular grafts (Park et al., 2016; Sah and Rath, 2016; Ruff et al., 2018; Hincke, 2019; Jalili-Firoozinezhad et al., 2020; Kulshreshtha et al., 2020).

ESM is a natural source of proteins, such as glucosamine and glycosaminoglycans, elastin, collagen (type I, V, X), hyaluronic acid, and other components that are related to the joint cartilage. The degradation of cartilage during osteoarthritis leads to bones rubbing, causing pain. ESM-based supplements were suggested to be used to slow down the progression of the disease. ESM suppresses the production of IL- $1 \beta$ and TNF- $\alpha$ inflammatory cytokines, subsiding inflammation (Hewlings et al., 2019). The double-blind and placebo study by Gil-Quintana et al. (2018) on the effect of daily intake of ESM supplement displayed shortterm effects within the first 3 days. Joint pain was significantly reduced, as was joint dysfunction. In a randomized, double-blind, placebo-controlled clinical trial (Hewlings et al., 2019) the intake of water-soluble chicken eggshell membrane hydrolysate dietary supplement significantly reduced the joint stiffness in adults with knee osteoarthritis by the $5^{\text {th }}$ day of supplementation. One of the possible reasons for the development of osteoarthritis is the excessive presence of free radicals in the body. As osteoarthritis cannot be cured at the present time, early prevention of osteoarthritis is preferable to subsequent treatment. Antioxidant protection is considered to be amongst the most effective prevention methods. It has been shown that peptide fractions obtained by the enzymatic hydrolysis of ESM with $\mathrm{Na}_{2} \mathrm{SO}_{3}$ and alkaline protease combinations cope well with this task (Zhao et al., 2019b). After the separation, the identified watersoluble peptides with ESYHLPR and MFAEWQPR ${ }^{2}$ amino acid sequences exhibited the best antioxidant activities and could be used as highly efficient antioxidant agents.

Another interesting ESM application is its use in a wavy small-diameter vascular graft (Yan et al., 2020a,b). The internal membrane with the ESM surface modified with heparin and dopamine exhibited improved anticoagulation properties, simultaneously promoting human umbilical vein endothelial cell proliferation in vitro. The desired mechanical properties were provided by the formation of the composite with elastic thermoplastic polyurethane fibers.

Another important biomedical application of the ESM is wound healing (Balassa, 1971; Dawson, 2003; Sandri et al., 2013; Jun et al., 2014; Guarderas et al., 2016; Kiselioviene et al., 2016; Tummalapalli et al., 2016; Kuruoglu, 2017; Schmidt et al., 2017; Vuong et al., 2017, 2018; Kenny et al., 2018; Salah et al., 2018; Saporito et al., 2018; Augustine et al., 2019; Blaine and Thang, 2019; Huang et al., 2020; Kulshreshtha et al., 2020). Non-healing wounds are a major health problem worldwide and a significant cause of morbidity and mortality. Cutaneous wounds caused by burns, trauma, or other conditions, such as diabetic foot ulcers, can lead to serious infections, body fluid loss, as well as major medical burdens (Ahmed et al., 2019b). Effective treatments for

\footnotetext{
${ }^{2}$ Characters in the abbreviations encoding the amino acid residues: E - Glutamic acid, S - Serine, $\mathrm{Y}$ - Tyrosine, $\mathrm{H}$ - Histidine, L - Leucine, $\mathrm{P}$ - Proline, R - Arginine, M - Methionine, F - Phenylalanine, A - Alanine, W - Tryptophan, Q - Glutamine.
} 
acute and chronic skin wounds are the focus of intensive research. ESM is supposed to offer great solution also as a topical ingredient in skincare applications to maintain skin health by reducing bacterial infections and inflammation (Kulshreshtha et al., 2020).

ESM was used as an integral component of various formulations, to enhance wound healing, facilitate rapid endothelialization and anticoagulation (Yan et al., 2020a). It was suggested as an important component of various woundcare dressings (Guarderas et al., 2016; Kiselioviene et al., 2016; Li et al., 2016, 2019b,c; Krishnan et al., 2020). ESM was also used to produce hybrid nanofibrous scaffolds for cutaneous tissue engineering (Mohammadzadeh et al., 2019), materials for periodontal tissues (Motoji et al., 2020), and for sciatic nerve regeneration (Farjah et al., 2020). The nanofibrous scaffolds based on the natural extracellular matrix promote the dynamics of skin progenitor cells and accelerate differentiation into mature keratinocytes (Mohammadzadeh et al., 2019).

A wound dressing should act as a skin barrier during the wound healing process. Ideally, it should promote wound healing and prevent bacterial infection. It should exhibit good biocompatibility and appropriate porosity, as well as effective antibacterial activity (Liu et al., 2020b). Only few clinical products can meet all these needs due to their mono-functionality, relatively complicated preparation procedures, and high cost. Developing such an ideal wound dressing for tissue regeneration remains a significant challenge. Natural materials are often multifunctional, owing to their complex composition and structure; ESM is no exception in this respect. Its successful use in various capacities for wound healing has been documented in numerous original research papers, reviews, book chapters, and books, as well as patents (Balassa, 1971; Dawson, 2003; Sandri et al., 2013; Jun et al., 2014; Guarderas et al., 2016; Kiselioviene et al., 2016; Tummalapalli et al., 2016; Kuruoglu, 2017; Schmidt et al., 2017; Vuong et al., 2017, 2018; Kenny et al., 2018; Salah et al., 2018; Saporito et al., 2018; Augustine et al., 2019; Blaine and Thang, 2019; Huang et al., 2020;
Kulshreshtha et al., 2020). Still, the mechanisms of action of the ESM and its role in the already successfully tested materials for wound healing remains hardly explored. Most likely, there is no single mechanism, and depending on the formulation and the application, the ESM can be either an active ingredient or an excipient.

ESM contains an abundance of antimicrobial, immunomodulatory, and other bioactive proteins, peptides, amino acids, collagen-like proteins, enzymes, and glycosaminoglycans (Yamauchi et al., 2013; Yoo et al., 2014; Benson et al., 2016; Jensen et al., 2016; Ahmed et al., 2017, 2019a,b; Niu et al., 2017; Dubourdieu, 2019; Gautron et al., 2019; Zhao et al., 2019b; Zhu, 2020). Each of them can have a pronounced influence on wound healing as a biologically active compound. Proteoglycans in ESM have been used successfully in treating non-healing wounds and burns, due to their biocompatibility, biodegradability, and similarity to macromolecules found in the human body (Benson et al., 2016; Mohammadzadeh et al., 2019).

Collagen (several types, in particular I, V, X) was named as one of the components that accounts for the biological activity of ESM (Yamauchi et al., 2013; Benson et al., 2016; Tummalapalli et al., 2016; Ahmed et al., 2017, 2019a,b; Dubourdieu, 2019; Mohammadzadeh et al., 2019; Farjah et al., 2020; Liu et al., 2020b; Motoji et al., 2020). ESM exerts an anti-aging effect by increasing type III collagen levels (Motoji et al., 2020). ESM has been shown to upregulate the expression of both collagen types I and III (Yamauchi et al., 2013).

Proteomic analysis of processed eggshell membrane powder (PEP) identified 110 proteins, including structural proteins such as collagen and cysteine-rich eggshell membrane proteins (CREMPs) that together constitute about $40 \%$ of PEP. Functional annotation clustering showed various predicted functionalities related to wound healing, including response to an external stimulus, defense response, inflammatory response, and cellsubstrate adhesion (Ahmed et al., 2017, 2019a,b).

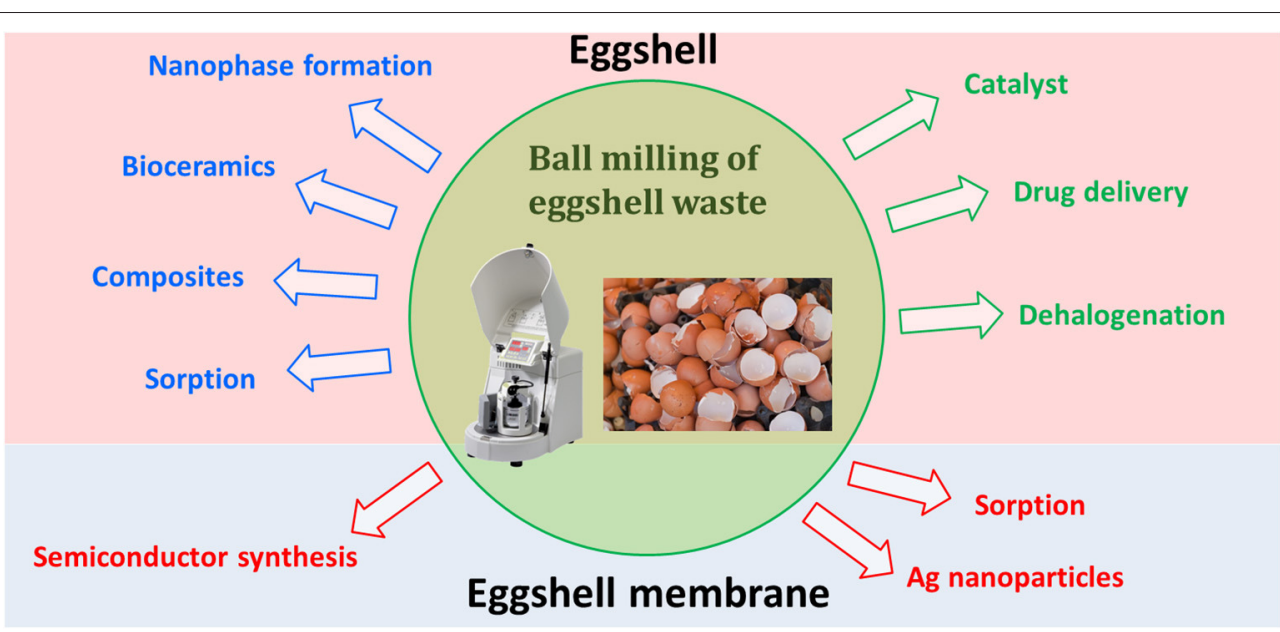

FIGURE 6 | Various applications of eggshell and its membrane subjected to mechanochemical treatment. Reprinted from Baláž (2018), Copyright (2018), with permission from Elsevier. 
TABLE 1 | Overview of research studies applying a mechanochemical approach for the treatment of eggshell waste published recently: experimental techniques, the most important result and application field of the final product.

\begin{tabular}{|c|c|c|c|c|}
\hline Milling input & Experimental techniques & Most important results & $\begin{array}{l}\text { Final product/ } \\
\text { application }\end{array}$ & References \\
\hline Eggshell & SEM & $\begin{array}{l}\text { Statistical approach; milling speed is the } \\
\text { most important factor }\end{array}$ & Hydroxyapatite/bioceramics & (van Hoten et al., 2018) \\
\hline $\begin{array}{l}\text { Eggshell + } \\
\text { ethanol/water }\end{array}$ & $\begin{array}{l}\text { XRD, SEM, TEM, TA, optical } \\
\text { microscopy, mechanical } \\
\text { properties evaluation, } \\
\text { biocompatibility }\end{array}$ & $\begin{array}{l}5 \text { wt } \% \text { nanohydroxyapatite was the ebst, } \\
\text { cells grow on the fibers }\end{array}$ & $\begin{array}{l}\text { PLA-nanohydroxyapatite } \\
\text { fibers/bioengineering }\end{array}$ & (Apalangya et al., 2019) \\
\hline $\begin{array}{l}\text { Eggshell }+ \\
\text { window parapet } \\
\text { made of PVC }\end{array}$ & XRD, FTIR, titration & $\begin{array}{l}\text { Comparison of planetary and vibratory } \\
\text { milling, scalability }\end{array}$ & $\begin{array}{l}\text { Calcium chloride }+ \text { harmless organic } \\
\text { matrix/dechlorination }\end{array}$ & (Baláž et al., 2019a) \\
\hline $\begin{array}{l}\text { Eggshell + } \\
\mathrm{TiO}_{2} /+\mathrm{Mg}\end{array}$ & XRD, TA, SEM & $\begin{array}{l}\text { Comparison of conventional and } \\
\text { high-energy ball milling }\end{array}$ & $\mathrm{CaTiO}_{3}$ ceramics/electronics & $\begin{array}{l}\text { (Cherdchom et al., } \\
\text { 2019) }\end{array}$ \\
\hline $\begin{array}{l}\text { Eggshell/cuttlefish } \\
\text { bone+ } \\
\text { phosphoric acid }\end{array}$ & SEM, XRD, Raman, TEM & $\begin{array}{l}\text { No sintering, comparison of eggshell and } \\
\text { cuttlefish bone as Ca sources }\end{array}$ & Hydroxyapatite/bioceramics & $\begin{array}{l}\text { (Ferro and Guedes, } \\
\text { 2019) }\end{array}$ \\
\hline $\begin{array}{l}\text { Eggshell + rice } \\
\text { straw }\end{array}$ & $\begin{array}{l}\text { XRD, SEM, adsorption kinetics } \\
\text { and thermodynamics and } \\
\text { influence of various factors }\end{array}$ & $\begin{array}{l}\text { Maximum sorption capacity of } 231 \mathrm{mg} / \mathrm{g} \\
\text { was evidenced for balanced eggshell:rice } \\
\text { straw ratio }\end{array}$ & $\begin{array}{l}\text { Phosphate ions adsorbent/wastewater } \\
\text { treatment }\end{array}$ & (Liu et al., 2019) \\
\hline $\begin{array}{l}\text { Eggshell + } \\
\text { acetone }\end{array}$ & XRD, SEM & $\begin{array}{l}\text { Sintering enriched Ca content and did not } \\
\text { result in a significant increase in crystallite } \\
\text { size }\end{array}$ & Nanoization & $\begin{array}{l}\text { (Puspitasari et al., } \\
\text { 2019) }\end{array}$ \\
\hline $\begin{array}{l}\mathrm{CaO} \text { from } \\
\text { eggshell }\end{array}$ & $\begin{array}{l}\text { XRD, FTIR, SEM, fluorescent } \\
\text { microscopy, biocompatibility } \\
\text { evaluation }\end{array}$ & $\begin{array}{l}\text { Comparison of ball milling, mortar and } \\
\text { pestle and Food and Drug Administration } \\
\text { (FDA)-approved methodology, post-milling } \\
\text { reaction with } \mathrm{H}_{3} \mathrm{PO}_{4}\end{array}$ & $\begin{array}{l}\beta \text {-tricalcium phosphate } \\
\text { scaffolds/bioceramics }\end{array}$ & $\begin{array}{l}\text { (Roopavath et al., } \\
\text { 2019) }\end{array}$ \\
\hline $\begin{array}{l}\text { CaO from } \\
\text { eggshell }\end{array}$ & $\begin{array}{l}\text { XRD, SEM, chemical oxygen } \\
\text { demand, biogas and methane } \\
\text { production }\end{array}$ & $\begin{array}{l}\text { Size reduction into nano-range resulted in } \\
\text { a significant improvement in biogas } \\
\text { production }\end{array}$ & $\begin{array}{l}\text { Biogas production from palm oil mill } \\
\text { effluent: cow manure mixture }\end{array}$ & (Sari et al., 2020) \\
\hline $\begin{array}{l}\text { Eggshell + } \\
\text { ethanol }\end{array}$ & XRD, FTIR, SEM, WCA, SPM & $\begin{array}{l}\text { Stearic acid favors the transformation into } \\
\text { aragonite }\end{array}$ & Superhydrophobic eggshell/filtration & (Seeharaj et al., 2019) \\
\hline $\begin{array}{l}\text { Eggshell }+\mathrm{Li}- \\
\mathrm{Ni}_{0.8} \mathrm{Co}_{0.1} \mathrm{Mn}_{0.1} \mathrm{O}_{2}\end{array}$ & $\begin{array}{l}\text { TA, XRD, FTIR, SEM/EDS, XPS, } \\
\text { electrochemical measurements }\end{array}$ & $\begin{array}{l}\mathrm{CaO} \text { prevents electrolyte dissolution and } \\
\text { electrode corrosion }\end{array}$ & $\begin{array}{l}\mathrm{CaO} \text {-coated } \mathrm{Li}_{-} \mathrm{Ni}_{0.8} \mathrm{Co}_{0.1} \mathrm{Mn}_{0.1} \mathrm{O}_{2} \\
\text { electrode/electrochemistry }\end{array}$ & (Senthil et al., 2019) \\
\hline $\begin{array}{l}\text { Eggshell + } \\
\text { acetone }\end{array}$ & XRD, SEM, FTIR & $\begin{array}{l}\text { Comparison of calcined }(\mathrm{CaO}) \text { and } \\
\text { non/calcined }\left(\mathrm{CaCO}_{3}\right) \text { material }\end{array}$ & Nanoization & (Supriyanto et al., 2019) \\
\hline $\begin{array}{l}\text { Eggshell + } \\
\text { stearic } \\
\text { acid/water }\end{array}$ & XRD, TA, TEM & $\begin{array}{l}\text { Stearic acid reduces the crystallite size } \\
\text { and thermal degradation temperature }\end{array}$ & Nanoization & $\begin{array}{l}\text { (Villarreal-Lucio et al., } \\
\text { 2019) }\end{array}$ \\
\hline $\begin{array}{l}\text { Eggshell }+ \\
\text { aqueous solution } \\
\text { of phosphate } \\
\text { precursor }\end{array}$ & XRD, FTIR, SEM, TA & $\begin{array}{l}\text { Pure HA produced from different } \\
\text { precursors using three different } \mathrm{CaCO}_{3} \\
\text { sources using wet milling and } \\
\text { low-temperature treatment }\end{array}$ & Hydroxyapatite/bioceramics & (Cestari et al., 2020) \\
\hline $\begin{array}{l}\text { Eggshell }+ \\
\text { ethanol }\end{array}$ & $\begin{array}{l}\text { SBET, particle size distribution, } \\
\text { zeta potential, SEM, TEM, EDS, } \\
\text { FIIR, } \mathrm{Ca}^{2+} \text { concentration } \\
\text { determination, XRD }\end{array}$ & $\begin{array}{l}\text { Zeta potential was decreased during } \\
\text { treatment }\end{array}$ & Nanoization & (Huang et al., 2020) \\
\hline $\begin{array}{l}\text { Eggshell } \\
\text { membrane }+ \\
\mathrm{Li}_{2} \mathrm{FeSiO}_{4}\end{array}$ & $\begin{array}{l}\text { XRD, TA, S } S_{B E T} \text {, Raman, XPS, } \\
\text { TEM }\end{array}$ & $\begin{array}{l}\text { ESM served as a carbon source for } \\
\text { improving electrical properties of the LFS } \\
\text { ESM composite }\end{array}$ & LFS-C composite/electrochemistry & (Karuppiah et al., 2020) \\
\hline $\begin{array}{l}\text { Eggshell + } \\
\mathrm{Al}_{2} \mathrm{O}_{3}\end{array}$ & $\begin{array}{l}\text { SEM, mechanical properties, } \\
\text { corrosion, thermal expansion }\end{array}$ & $\begin{array}{l}\text { Toughness and ductility reduced, but } \\
\text { tensile strength, hardness, corrosion } \\
\text { resistance, thermal stability improved upon } \\
\text { addition of } \mathrm{CaO} \text { derived from eggshell }\end{array}$ & $\mathrm{Al} /$ eggshell/ $/ \mathrm{Al}_{2} \mathrm{O}_{3}$ composite & $\begin{array}{l}\text { (Kumar, S., Dwivedi, S. } \\
\text { P., and Dwivedi et al., } \\
\text { 2020) }\end{array}$ \\
\hline Eggshell & $\begin{array}{l}\text { Particle size distribution, SEM, } \\
\text { EDX, XRD }\end{array}$ & The authors report graphite in the eggshell & Micronization & $\begin{array}{l}\text { (Ononiwu and Akinlabi, } \\
\text { 2020) }\end{array}$ \\
\hline $\begin{array}{l}\text { Eggshell/eggshell } \\
+\mathrm{TiO}_{2}\end{array}$ & $\begin{array}{l}\text { FTIR, TEM, XRD, acid-resistant } \\
\text { and buffering properties }\end{array}$ & $\begin{array}{l}\text { The buffering performance was evaluated } \\
\text { against that of four available toothpastes }\end{array}$ & Eggshell- $\mathrm{TiO}_{2}$ composite/dentistry & (Onwubu et al., 2019a) \\
\hline
\end{tabular}


TABLE 1 | Continued

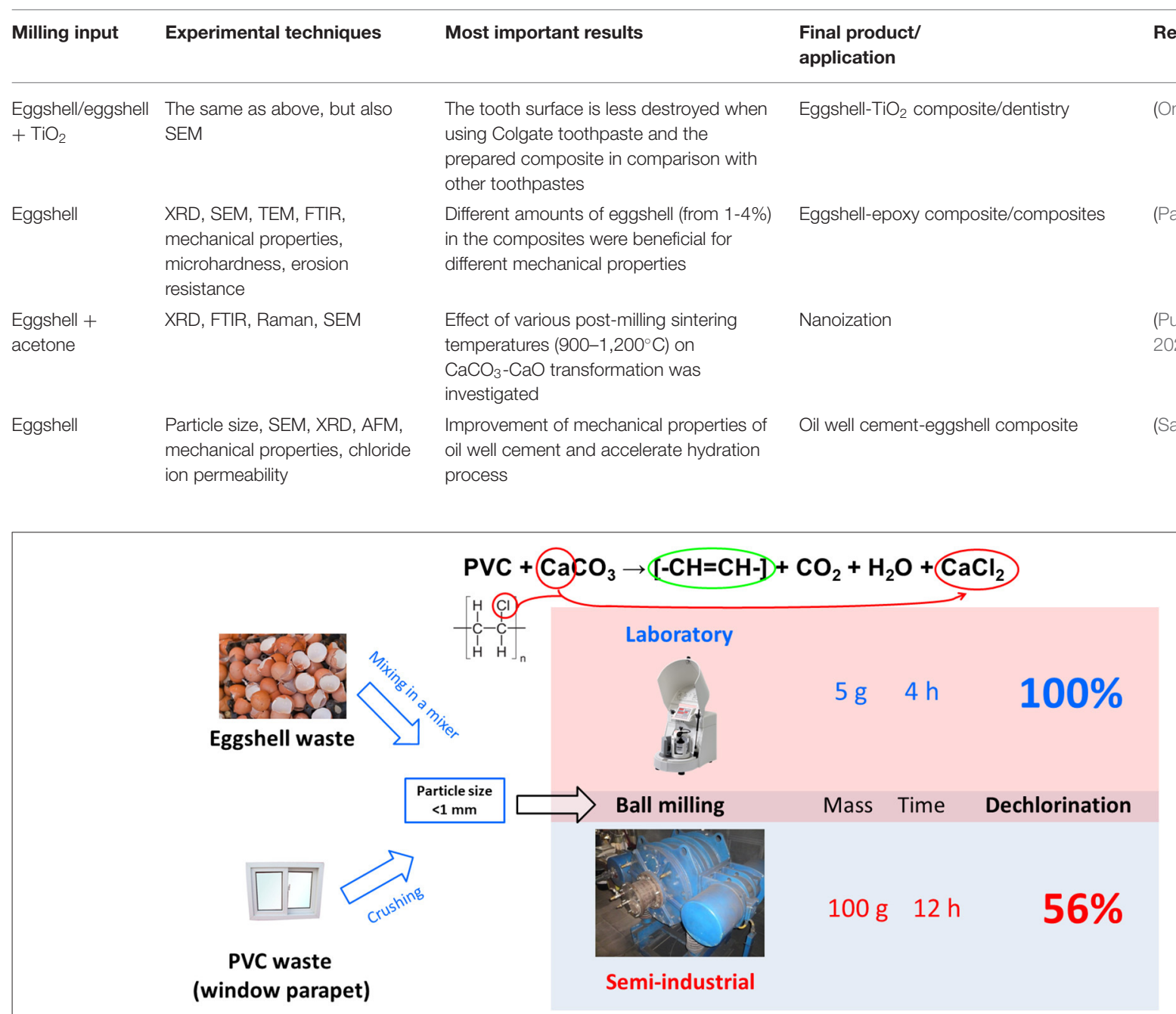

FIGURE 7 | Schematic illustration of main idea and results of the laboratory and semi-industrial dechlorination of PVC waste using eggshell. Reprinted from Baláž et al. (2019a), Copyright (2019), with permission from Elsevier.

The presence of essential structural proteins such as osteopontin, sialoprotein, keratin, proteoglycans, and glycoproteins has been previously proved (Wong et al., 1984; Chowdhury, 1990; Arias et al., 1991; Nakano et al., 2003; Zhao and Chi, 2009; Hincke et al., 2012; Dombre et al., 2017; Silva et al., 2018). Also, ESM harbors numerous natural glycoproteins, notably glucosamine, chondroitin, and hyaluronic acid, which are applicable for the cutaneous wound dressings (Mohammadzadeh et al., 2019).

The ESM enzymatic hydrolysate possesses a remarkable antibacterial activity (Yoo et al., 2014; Niu et al., 2017). A hydrolyzed water-soluble ESM product triggered upregulation of antioxidant-response elements in human keratinocytes, and significantly reduced production of reactive oxygen species by polymorphonuclear (PMN) cells in vitro. Furthermore, human dermal fibroblasts treated with soluble ESM in vitro showed an increase in the production and secretion of collagen and elastin (Benson et al., 2016; Augustine et al., 2019). Usually, the enzymatic hydrolysis is used to obtain solubilized proteins because both acid and basic hydrolysis destroy some constituents, decreasing the nutritional value of proteins (García and González, 2020). Solubilization of ESM, however, requires a more complicated approach due to the high resistance of ESM to the enzymes. In the study by García and González (2020), denaturing agent with detergent properties (sodium lauryl sulfate or taurocholate)/reducing agent (dithiothreitol and sodium metabisulfite) compositions were patented to break disulfide bridges of ESM proteins and provide access to the enzymes (cysteine proteases), facilitating the hydrolysis.

In many studies the ESM is used as a template or framework, forming a composite with bioactive molecules or nanoparticles embedded into its structure (Jun et al., 2014; Li et al., 2016, 2019b; Puertas-Bartolome et al., 2018; Augustine et al., 2019; Raz et al., 2019; Farjah et al., 2020; Krishnan et al., 2020; Selvam et al., 
2020). Consisting of unique interwoven shell membrane fibers, the ESM provides a unique supporting platform for functional nanoparticles in catalysis and sensing (Vuong et al., 2017). The same or similar materials can be used for wound healing. The flexible and highly pure microfibrous network structure of the ESM can be used as an artificial extracellular matrix (ECM) platform for engraftment or as a tissue-engineered scaffold (Vuong et al., 2017, 2018; Park et al., 2019; Liu et al., 2020b).

Flexible and functional scaffolds were constructed, for example using an ESM and graphene. The graphene-layered ESM (GEM) scaffolds showed better mechanical and hydrophilic properties than those of a raw ESM. The GEM scaffolds can control the adhesion properties of stem cells, enhancing the proliferation and osteogenic properties of the cells as compared to the effects of a raw ESM. Additionally, the GEM scaffolds can improve the secretion of growth factors from stem cells, possibly through enhanced cell-substrate interactions, thereby promoting the proliferation and differentiation of these cells (Park et al., 2019). Physical and biochemical features of a collagen membrane can be significantly improved by conjugating it with soluble ESM proteins (Ino et al., 2006).

Some studies emphasize the positive effect of lycopene on ESM guidance channels in sciatic nerve regeneration in rats, with ESM acting as a nerve guidance channel (NGC). Ideally, NGC

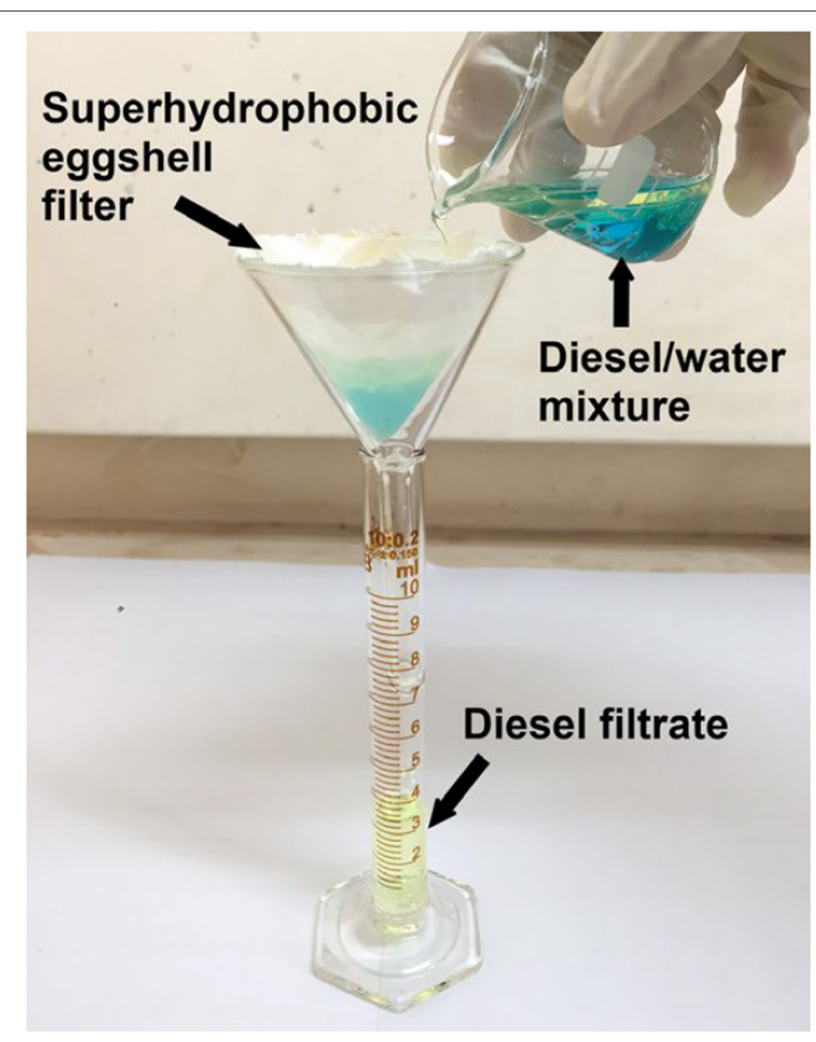

FIGURE 8 | A photograph of the experimental setup for diesel/water separation test (water was dyed blue with methylene blue for better contrast) (Seeharaj et al., 2019) copyright 2019. The American Ceramic Society. must be biodegradable, biocompatible, flexible, semipermeable, easily made and sterilized, and be amenable to long-term storage. A composite of the ESM with lycopene meets all of these requirements. There are many benefits of using an ESM channel, including low cost and flexibility. Moreover, ESM is strong enough to maintain a suture. In addition, the dimensions of the channel are easily controlled. At the same time, the ESM is not merely a "guiding structure." As was mentioned above, it contains several types of collagen, hyaluronic acid, and laminin. These biologically active compounds are important in nerve regeneration (Farjah et al., 2020).

Another example of using the ESM as a framework for a biologically active composite is to use it as a porogen of the chitosan-based macroparticles, which are used to immobilize protease. Chitosan-based macroparticles are a common carrier for enzyme immobilization that is applied in the food industry. Driven by the requirement of large carrier pores for the biomacromolecular substrates, such as a protein, the eggshell membrane powder (ESMP) was employed as a multifunctional porogen to improve the physicochemical structure of chitosanbased macroparticles. The results showed that an increase of ESMP percentage could improve the porosity of macroholes in macroparticles, and it also enlarged the size of mesopores. Moreover, the ESMP significantly increased the amount of papain immobilization, whereas the specific activity of immobilized papain went through a maximum with the increase of ESMP. The inclusion of $20 \%$ ESMP in chitosan-based macroparticles gave the highest activity of its immobilized protease (Liu et al., 2020b). The ESM-chitosan blend films were also used as wound-care dressings (Li et al., 2019c).

Composites of ESM with nanoparticles of biologically active compounds, such as metal oxides or metals, were successfully applied for wound healing. $\mathrm{CdO} / \mathrm{ZnO}-\mathrm{ESM}$ nanocomposites were shown to have an exceptional antimicrobial activity against both Gram-positive and Gram-negative bacteria (Selvam et al., 2020). A copper-containing bioactive glass (Cu-BG) nanocoating $(40-50 \mathrm{~nm})$ with a uniform nanostructure was formed on a natural eggshell membrane (Cu-BG/ESM) by pulsed laser deposition (PLD). It was characterized by improved angiogenesis, antibacterial activity, and wound healing. The surface physicochemical properties, including the hydrophilicity and the hardness of ESM, were significantly improved after depositing $\mathrm{Cu}-\mathrm{BG}$ nanocoatings. The 5Cu-BG/ESM films (containing $5 \mathrm{~mol} \% \mathrm{Cu}$ ) could maintain a sustained release of $\mathrm{Cu}^{2+}$ ions and distinctly inhibit the viability of bacteria (Escherichia coli) (Li et al., 2016).

An antibacterial nanobiomaterial for wound-care based on the absorption of silver nanoparticles (Ag NPs) on the ESM was proposed in Raz et al. (2019), Li et al. (2019b), and Krishnan et al. (2020). The addition of Ag NPs changed the ESM from hydrophobic to hydrophilic, which is important for the woundhealing process. The Ag NPs/ESM composites had a higher surface area $\left(159.08 \mathrm{~m}^{2} / \mathrm{g}\right)$, than the natural ESM $\left(24.32 \mathrm{~m}^{2} / \mathrm{g}\right)$ and a suitable average pore size $(10.92 \mathrm{~nm})$. Hence, Ag NPs/ESM composites displayed better absorption and antibacterial abilities (Krishnan et al., 2020). Several techniques to produce composite materials based on ESM and Ag NPs have been reported. 
One of them includes pre-treating the eggshell membrane with procyanidin to reduce silver ions into nanoparticles, which are then incorporated into the membrane structure. Such materials showed antibacterial activity against $S$. aureus, S. albus, and $E$. coli when tested on bacterial plates (Krishnan et al., 2020).

Some ESM-based antibacterial materials for wound healing contain both metal and metal oxide nanoparticles. A challenge in fabricating such materials is to produce an effective carrier or delivery matrix to achieve a sustained release profile with high bactericidal efficacy along with good cytocompatibility. A facile route has been proposed to fabricate a hierarchical nanobiocomposite with effective loading of $\mathrm{ZnO} /$ silver nanoparticles (Ag NPs) to attain excellent bactericidal efficacy with a good and sustainable release profile. In the mentioned study, surface-functionalized eggshell membranes (ESM) were deployed as three-dimensional loading matrices for efficient loading of $\mathrm{ZnO} / \mathrm{Ag} \mathrm{NPs}$ (Raz et al., 2019). A simple sonochemically guided approach was adopted to synthesize $\mathrm{ZnO}$ nanoflakes in situ onto the microfibrous ESM and decorate them with Ag NPs, thereby forming a nanobiocomposite. The microstructural analysis confirmed the successful anchorage of $\mathrm{ZnO}$ nanoflakes and $\mathrm{Ag} \mathrm{NPs}$ on microfibrous eggshell membrane, thus reinstating the hierarchical morphology of the nanobiocomposites. Owing to the synergistic activity of $\mathrm{ZnO}$ and Ag NPs, the nanobiocomposites demonstrated exceptional bactericidal activity against Gram-negative, E. coli or $P$. aeruginosa, and Gram-positive, S. aureus or B. subtilis, bacterial cells. Furthermore, direct exposure of nanobiocomposites with NIH 3T3 cells revealed the biocompatible nature of developed matrices. Prolonged exposure also indicated that the 3T3 cells tend to adhere onto the microfibrous nanobiocomposite without any observable deformation in cellular morphology. The architectural tribology and excellent bactericidal performance of the nanobiocomposites along with their cytocompatible nature manifested its potential as an alternative platform for various biomedical applications.

There are also examples when ESM is embedded into another matrix. For example, ethanol-lubricated expandedpolytetrafluoroethylene vascular grafts loaded with an eggshell membrane extract and heparin were applied for rapid endothelialization and anticoagulation (Yan et al., 2020b). This novel ethanol-water lubricant not only evenly dispersed the ESM extract but also dissolved the heparin sodium. The as-fabricated synthetic expanded polytetrafluorethylene (ePTFE) grafts, which are routinely used for vascular repair and reconstruction, showed the classic node-fiber structure suitable for cell adhesion and migration. The embedded ESM extract and heparin improved the hydrophilicity and cytocompatibility, resulting in enhanced cell viability and proliferation of human umbilical vein endothelial cells (HUVECs) (Yan et al., 2020b).

Chitosan films enriched with the ESM powder were produced in Santos et al. (2019), Li et al. (2019c), and Liu et al. (2020b). Their thermal, chemical, biological, and mechanical properties were studied and the films were shown to be suitable for biomedical applications (Santos et al., 2019).

An example of a complex composite containing ESM is provided by a biodegradable dual porous PLA-PVA coreshell fiber, enriched with ESM, into which a connective tissue growth factor (CTGF) is also incorporated (Augustine et al., 2019). CTGF is a signaling molecule with several roles in tissue repair and regeneration including promoting cell adhesion, cell migration, cell proliferation, and angiogenesis. The

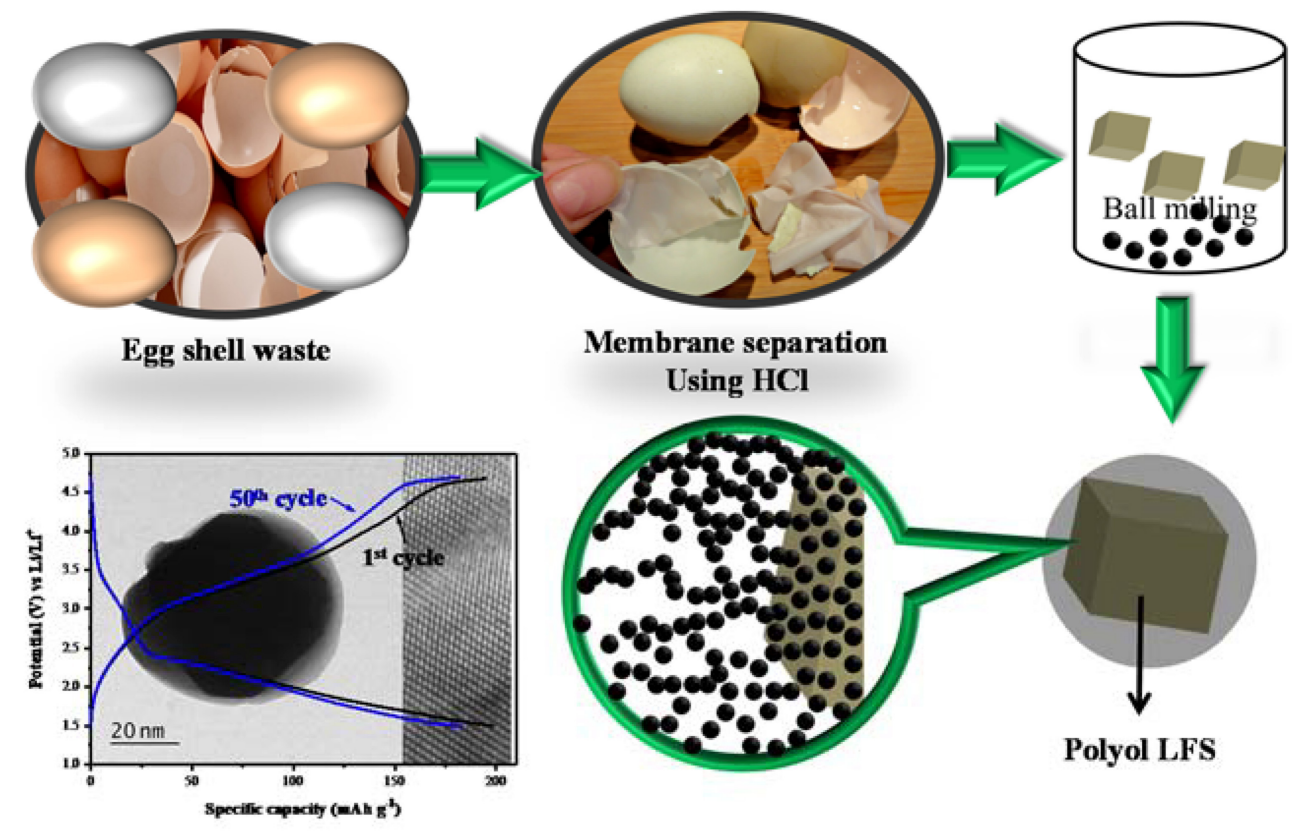

FIGURE 9 | Schematic illustration of the procedure leading to the production of $\mathrm{Li}_{2} \mathrm{FeSiO}_{4} / \mathrm{C}$ composite with good electrical properties (Karuppiah et al., 2020). 
incorporation of CTGF into a fiber facilitates its sustained release. The membranes were fabricated by a core-shell electrospinning technique. CTGF was entrapped within the PVA core which was coated by a thin layer of PLA. This biomaterial can be used to treat diabetic wounds (Augustine et al., 2019).

As another example, one can mention the nanofibrous scaffolds composed of a blend of poly( $\varepsilon$-caprolactone) (PCL), silk fibroin (SF), soluble eggshell membrane (SESM), and Aloe vera (AV) gel (Mohammadzadeh et al., 2019). Such composites were also developed by electrospinning. These scaffolds were applied for cutaneous tissue engineering. The artificial scaffolds were modulated with natural biopolymers, including the ESM as one of them. In the natural ESM, cross-linked disulfide bonds limit the solubility of ESM and its use in biomedical engineering as the nanofibrous scaffold. Soluble ESM (SESM) can be prepared, but it has poor mechanical properties because of its low molecular weight and wide molecular weight dispersion. Therefore, it is difficult to obtain a nanofibre or film from pure ESM. Adding $\operatorname{poly}(\varepsilon-$ caprolactone) (PCL) to the composite materials improves the mechanical properties, without deterioration of biocompatibility (Mohammadzadeh et al., 2019).

\section{Limitations}

Summing up, one can note that most publications on the biomedical applications of the ES and ESM either report the preparative techniques of producing a material, or document the results of its in vitro and in vivo testing. Despite many impressive examples of successful applications of these materials, little remains known about the underlying mechanisms of action. This field looks like a terra incognita for solid-state physical chemists and can promise many exciting fundamental discoveries, if biochemical, medical, and solid-state research is carried out jointly by interdisciplinary teams.

One of the technological challenges when producing an ESMbased material is to separate ESM from the shell. The poor solubility of ESM limits the bioavailability of its constituents and reduces the expression of their potential bioactivity. This problem can be overcome, for example by cryo-grinding and homogenization. This reduces the particle size and produces a particalized eggshell membrane (PEM) approaching submicron dimensions, with enhanced anti-inflammatory and antimicrobial activity against skin-associated pathogens (Kulshreshtha et al., 2020).

\section{USING TOOLS OF MECHANOCHEMISTRY TO BOOST THE APPLICATION POTENTIAL OF EGGSHELL WASTE: AN UPDATE}

Mechanochemistry is already an established method in various research fields and is gaining more and more interest in the research world (Boldyrev and Avvakumov, 1971; Butyagin, 1971, 1994; Heinicke, 1984; Tkáčová, 1989; Gutman, 1998; Avvakumov et al., 2001; Boldyrev, 2006, 2018; Baláž, 2008; Zyryanov, 2008; Declerck et al., 2009; Guo et al., 2010; James et al., 2012; Baláž et al., 2013; Boldyreva, 2013; Braga et al., 2013; Groote et al.,
2013; Huot et al., 2013; Šepelák et al., 2013; Stolle and Ranu, 2014; Cagnetta et al., 2016; Andre et al., 2017; Colacino et al., 2018; Bolm and Hernandez, 2019; Bychkov et al., 2019; Gomollón-Bel, 2019; Rogachev, 2019; Suryanarayana, 2019; Tan and García, 2019; De Oliveira et al., 2020a,b), has recently been awarded on a European level by a COST project (Baláž et al., 2019b; Hernández et al., 2020; www.mechsustind.eu $)^{3}$ and is also recognized by IUPAC (Mcnaught and Wilkinson, 1997; Gomollón-Bel, 2019). International Mechanochemical Association is IUPAC-affiliated since 1988 (www.imamechanochemical.com/about-us/) ${ }^{4}$. The area of waste treatment is also interesting for the mechanochemical community (Lomovsky and Boldyrev, 2006; Guo et al., 2010; Tan and Li, 2015; Cagnetta et al., 2016; Bychkov et al., 2019; Li et al., 2019a; Piras et al., 2019). There are several papers that applied tools of mechanochemistry for the treatment of eggshell waste. A review paper on this topic was published in 2018 (Baláž, 2018). Ball milling was applied for four main purposes- formation of nanophase, synthesis of bioceramics, composite materials synthesis, and improvement in sorption properties. The broad application fields upon application of ball milling of eggshell waste can be well-seen from the graphical abstract of that paper (Figure 6).

Since the publication of the review article mentioned above, a couple of new works have appeared. The most important ones with their main findings are briefly reviewed in Table 1. As follows from the table, the authors targeted different application fields, however, the majority of them fall into the categories outlined in Figure 6. The works on bioceramics preparation and the preparation of nano-eggshell dominate. Nevertheless, some new application spheres have emerged, e.g., biogas production (Sari et al., 2020), filtration (Seeharaj et al., 2019), dentistry (Onwubu et al., 2019a,b), and electrochemistry (Cherdchom et al., 2019; Senthil et al., 2019; Karuppiah et al., 2020). A reference to the study using ball milling of eggshell for the application in catalysis (Mosaddegh and Hassankhani, 2014) has been already mentioned earlier. A few interesting reports are summarized in more detail below.

The idea of dechlorinating PVC waste using eggshell (containing both shell and membranes) was scaled up to a semiindustrial level and compared to a lab-scale process in Baláž et al. (2019a). The laboratory-scale experiment was more efficient, as complete dechlorination was observed upon $4 \mathrm{~h}$ of milling, whereas only $56 \%$ was reached after $12 \mathrm{~h}$ of treatment in a semiindustrial vibratory ball mill. However, the milling conditions in the vibratory mill were not optimized. The rate constant obtained using the best-fitting zero-order kinetic model for the scaled-up processing was also significantly lower. Chlorine originating from waste PVC was successfully bound to a deliquescent $\mathrm{CaCl}_{2}$. The idea, scale, and dechlorination result can be well-seen in Figure 7.

From the papers focusing on the bioceramics production, the report (Ferro and Guedes, 2019) is of particular interest,

\footnotetext{
${ }^{3}$ www.mechsustind.eu CA18112: Mechanochemistry for Sustainable Industry. Available online at: www.mechsustind.eu (accessed September 30, 2020).

${ }^{4}$ www.Imamechanochemical.Com/About-Us/ International Mechanochemical Association. Available online at: www.imamechanochemical.com/about-us/ (accessed September 30, 2020).
} 
as the authors succeeded in the preparation of hydroxyapatite just by using ball milling without the need of subsequent sintering. As calcium sources either eggshell or cuttlefish bones (containing $\mathrm{Ca}$ in the form of calcite or aragonite, respectively), have been applied. The reaction progress was found to be a function of energy input and was different for each precursor. The final product was formed easier when using an aragonitecontaining precursor.

Eggshell was co-milled with rice straw and subsequently heated at $800^{\circ} \mathrm{C}$ in order to obtain effective adsorbent of phosphate ions in Liu et al. (2019). The kinetics of the adsorption process can be well-described by a pseudo-second-order kinetics and the maximum adsorption capacity calculated from the adsorption isotherm using Langmuir model was $231 \mathrm{mg} / \mathrm{g}$ (evidenced for eggshell: rice straw 1:1 ratio). The adsorption ability of all three phosphate ions (including the hydrogenated ones) has been investigated, yielding the best results for hydrogen-free $\mathrm{PO}_{4}^{3-}$ ones, as the presence of hydrogen hampers the efficient complexation of $\mathrm{Ca}$ and $\mathrm{P}$. The elevated temperature improved the outcome, which, together with other results in the paper confirmed the chemical character of adsorption.

The hydrophobic eggshell waste was prepared by mechanical activation and subsequent modification with stearic acid mixed with polymer binder in Seeharaj et al. (2019). The obtained material was then dip-coated on glass and cotton fabric. As the resulting material exhibited the water contact angle values above $150^{\circ}$, it can be considered superhydrophobic. As a proof of the applicability, the separation of diesel/water mixture by filtration on the prepared material is shown in Figure 8. Whereas, diesel easily goes through to the filtrate, water remains on the filter.

Three different biogenic sources, namely eggshell (ES), cuttlefish bone (CB) and mussel shells (MS) have been used as sources of calcium to produce hydroxyapatite in Cestari et al. (2020). As a source of phosphates, mainly ammonium phosphate dibasic (APD) has been used. The XRD results showed that ES and MS contain mostly calcite and CB contains aragonite. On the contrary to Ferro and Guedes (2019), just milling did not yield the desired phases, however, a subsequent low-temperature treatment did. The temperatures in the range $120-150^{\circ} \mathrm{C}$ were sufficient to get the hydroxyapatite and the process seems to be the most straightforward (no intermediate phases) for the aragonite-containing CB precursors. Calcite phase could still be detected when using ES and MS, whereas pure HA was formed in the case of CB. Nevertheless, performing the reaction at low $\mathrm{pH}$ using phosphoric acid instead of APD yielded phase-pure hydroxyapatite also in the case of ES and MS precursors.

An interesting study showing the acid-resistant properties of the eggshell waste, which can be potentially applied in dentistry has been reported in Onwubu et al. (2019b). Enamels collected from bovine were exposed to the action of $\mathrm{HCl}$ in the presence of various toothpaste solutions and also to pure eggshell and eggshell- $\mathrm{TiO}_{2}$ composite. The acid-resistant properties could be well-traced from the SEM images of the enamels taken after the action of the corresponding solutions. Whereas, the enamels after the action of Colgate toothpaste, eggshell and eggshell/ $/ \mathrm{TiO}_{2}$ is smooth, it contains fractures and roughness, being the result of acid action in the other cases.

Lithium iron orthosilicate $\mathrm{Li}_{2} \mathrm{FeSiO}_{4}$ (LFS) was prepared using the polyol method and subsequently co-milled with eggshell membrane serving as a carbon source in Karuppiah et al. (2020). The complete carbonization of ESM was achieved during the post-milling calcination in Ar atmosphere and the successful coating with iron was proven by TEM. The as-received LFS/C composite exhibited excellent electrical properties with high coulombic efficiency of $98.5 \%$ which can be maintained for more cycles. The main message of the paper is demonstrated in Figure 9.

The calcined eggshell was used to produce biogas from palm oil mill effluent and cow manure mixture in Sari et al. (2020). Namely, the effect of the particle size reduction achieved by ball milling was investigated. The increasing amount of nanoCa led to the improvement of the performance, however, the excessive amount of calcium has a detrimental effect on the biogas production, as when Ca concentration is $10 \mathrm{~g} / \mathrm{L}$, the result is even worse than in the case of the control experiment.

Mechanochemical processing of eggshell waste still finds new applications spheres and as both mechanochemistry and eggshell waste can be considered sustainable and applicable for the protection of the environment, it is highly probable that this area will further expand in the future.

\section{Limitations}

Although the ball milling process is very beneficial in broadening the application scope of eggshell waste, it suffers from the traditional disadvantages of mechanochemistry, namely the contamination of the treated material with small fragments from milling balls and chambers and large temperature elevation at the contact points between the milled material and the milling balls. The latter phenomenon can lead to partial decarbonation of eggshell (it was already shown before that the decomposition temperature decreases with milling; Petkova et al., 2017), which might significantly alter the properties of the final product. However, in many cases, the production of $\mathrm{CaO}$ is necessary anyway, so it might also be beneficial. With regards to the eggshell membrane, the intensive milling degrades the soft fiber structure and can deteriorate adsorption properties (Baláž et al., 2016). However, upon proper tuning of the milling conditions (e.g., by using mild conditions when treating eggshell membrane), it is possible to avoid this undesirable phenomenon.

\section{CONCLUSION}

Nature provides us with a lot of useful materials and despite the fact that some of them might seem to be without further use, their hidden application potential is always being discovered. This also accounts for the eggshell waste, one of the most common food wastes. Rather than being discarded on the landfills, it can be very useful in a rich plethora of applications. This review aimed to show its applications in catalysis, electrochemistry, therapeutics and after proper treatment by an environmentally harmless mechanochemistry, the scope of its applications can be 
further broadened. A large number of publications on this topic has been published in the last 2-3 years, which clearly shows that eggshell waste has recently become a very interesting material for various research groups around the world.

\section{AUTHOR CONTRIBUTIONS}

MB proposed the main idea and wrote the introductory part, a chapter devoted to the mechanochemical treatment of eggshell waste and conclusions. DR and EB wrote the part dealing with biomedical applications of the ES and ESM. DR-P and RL wrote the part devoted to the use of eggshell catalysis of bioactive compounds preparation, photocatalysis, and other environmentally beneficial applications. SP wrote the part devoted to the catalysis of biofuels using eggshell waste. TM wrote the part devoted to electrochemical applications of eggshell. All authors contributed to the article and approved the submitted version.

\section{REFERENCES}

Ahmed, T. A. E., Suso, H.-P., and Hincke, M. T. (2017). In-depth comparative analysis of the chicken eggshell membrane proteome. J. Proteomics 155, 49-62. doi: 10.1016/j.jprot.2017.01.002

Ahmed, T. A. E., Suso, H.-P., and Hincke, M. T. (2019a). Experimental datasets on processed eggshell membrane powder for wound healing. Data Brief 26:104457. doi: 10.1016/j.dib.2019.104457

Ahmed, T. A. E., Suso, H.-P., Maqbool, A., and Hincke, M. T. (2019b). Processed eggshell membrane powder: bioinspiration for an innovative wound healing product. Mater. Sci. Eng. CMater. Biol. Appl. 95, 192-203. doi: 10.1016/j.msec.2018.10.054

Alcaraz-Espinoza, J. J., De Melo, C. P., and De Oliveira, H. P. (2017). Fabrication of highly flexible hierarchical polypyrrole/carbon nanotube on eggshell membranes for supercapacitors. Acs Omega 2, 2866-2877. doi: 10.1021/acsomega.7b00329

Alsohaimi, I. H., Nassar, A. M., Elnasr, T.A.S., and Cheba, B.A. (2020). A novel composite silver nanoparticles loaded calcium oxide stemming from egg shell recycling: a potent photocatalytic and antibacterial activities. J. Clean. Prod. 248:119274. doi: 10.1016/j.jclepro.2019.119274

Andre, V., Quaresma, S., Da Silva, J. L. F., and Duarte, M. T. (2017). Exploring mechanochemistry to turn organic bio-relevant molecules into metal-organic frameworks: a short review. Beilstein J. Org. Chem. 13, 2416-2427. doi: 10.3762/bjoc.13.239

Apalangya, V. A., Rangari, V. K., Tiimob, B. J., Jeelani, S., and Samuel, T. (2019). Eggshell based nano-engineered hydroxyapatite and poly(lactic) acid electrospun fibers as potential tissue scaffold. Int. J. Biomater. 2019:6762575. doi: $10.1155 / 2019 / 6762575$

Arias, J. L., Fernandez, M. S., Dennis, J. E., and Caplan, A. I. (1991). Collagens of the chicken eggshell membranes. Connect. Tissue Res. 26, 37-45. doi: $10.3109 / 03008209109152162$

Asgari, G., Faradmal, J., Nasab, H. Z., and Ehsani, H. (2019). Catalytic ozonation of industrial textile wastewater using modified $\mathrm{C}$-doped $\mathrm{MgO}$ eggshell membrane powder. Adv. Powder Technol. 30, 1297-1311. doi: 10.1016/j.apt.2019.04.003

Augustine, R., Zahid, A. A., Hasan, A., Wang, M., and Webster, T. J. (2019). CTGF loaded electrospun dual porous core-shell membrane for diabetic wound healing. Int. J. Nanomed. 14, 8573-8588. doi: 10.2147/IJN.S224047

Avvakumov, E. G., Senna, M., and Kosova, N. V. (2001). Soft Mechanochemical Synthesis: A Basis for New Chemical Technologies. Boston: Kluwer Academic Publishers.

Balassa, L. L. (1971). Process for Using Eggshell Compositions for Promoting Wound Healing. USA patent application US3558771A. Washington, DC: U.S. Patent and Trademark Office.

\section{FUNDING}

This work is a contribution to the COST Action CA18112 (Baláž et al., 2019b; Hernández et al., 2020, www.mechsustind. eu) supported by COST (European Cooperation in Science and Technology, www.cost.eu). MB acknowledges the support of the Slovak Research and Development Agency (contract No. APVV-18-0357) and Slovak Grant Agency VEGA (project No. 2/0044/18). EB and DR acknowledge financial support from Russian Ministry of Higher Education and Science (projects AAAA-A19-119020890025-3 and AAAA-A17117022250038-7). TM and SP acknowledge the support of the Ministry of Education, Science and Technological Development of the Republic of Serbia (Grant No. 451-0368/2020-14/200026). RL gratefully acknowledges MINECO as well as FEDER funds for funding under project CTQ201678289-P and financial support from the University of Cordoba (Spain).

Baláž, M. (2014). Eggshell membrane biomaterial as a platform for the applications in materials science. Acta Biomater. 10, 3827-3843. doi: 10.1016/j.actbio.2014.03.020

Baláž, M. (2018). Ball milling of eggshell waste as a green and sustainable approach: a review. Adv. Colloid Interface Sci. 256, 256-275. doi: 10.1016/j.cis.2018. 04.001

Baláž, M., Bujnáková, Z., Achimovičová, M., Tešinský, M., and Baláž, P. (2019a). Simultaneous valorization of polyvinyl chloride and eggshell wastes by a semi-industrial mechanochemical approach. Environ. Res. 170, 332-336. doi: 10.1016/j.envres.2018.12.005

Baláž, M., Ficeriová, J., and Briančin, J. (2016). Influence of milling on the adsorption ability of eggshell waste. Chemosphere 146, 458-471. doi: 10.1016/j.chemosphere.2015.12.002

Baláž, P. (2008). Mechanochemistry in Nanoscience and Minerals Engineering. Berlin; Heidelberg: Springer.

Baláž, P., Achimovičová, M., Baláž, M., Billik, P., Cherkezova-Zheleva, Z., Criado, J. M., et al. (2013). Hallmarks of mechanochemistry: from nanoparticles to technology. Chem. Soc. Rev. 42, 7571-7637. doi: 10.1039/c3cs35468g

Baláž, M., Vella-Zarb, L., Hernández, J. G., Halasz, I., Crawford, D. E., Krupička, M., et al. (2019b). Mechanochemistry: a disruptive innovation for the industry of the future. Chim. Oggi Chem. Today 37, 32-34.

Barros, F. J. S., Moreno-Tost, R., Cecilia, J. A., Ledesma-Munoz, A. L., De Oliveira, L. C. C., Luna, F. M. T., et al. (2017). Glycerol oligomers production by etherification using calcined eggshell as catalyst. Mol. Catal. 433, 282-290. doi: 10.1016/j.mcat.2017.02.030

Benson, K. F., Newman, R. A., and Jensen, G. S. (2016). Water-soluble egg membrane enhances the immunoactivating properties of an aloe vera-based extract of nerium oleander leaves. Clin. Cosmetic Invest. Dermatol. 9, 393-403. doi: 10.2147/CCID.S114471

Bharti, R., Guldhe, A., Kumar, D., and Singh, B. (2020). Solar irradiation assisted synthesis of biodiesel from waste cooking oil using calcium oxide derived from chicken eggshell. Fuel 273:117778. doi: 10.1016/j.fuel.2020. 117778

Blaine, R. C., and Thang, D. N. (2019). Wound Care Product With Eggshell Membrane. USA Patent application US10166260B2. Washington, DC: U.S. Patent and Trademark Office.

Blair, H. C., Robinson, L. J., Huang, C. L. H., Sun, L., Friedman, P. A., Schlesinger, P. H., et al. (2011). Calcium and bone disease. Biofactors 37, 159-167. doi: $10.1002 /$ biof.143

Boldyrev, V. V. (2006). Mechanochemistry and mechanical activation of solids. Russian Chem. Rev. 75, 177-190. doi: 10.1070/RC2006v075n03ABEH001205

Boldyrev, V. V. (2018). Mechanochemistry in Siberia. Herald Russian Acad. Sci. 88, 142-150. doi: $10.1134 /$ S1019331618020016 
Boldyrev, V. V., and Avvakumov, E. G. (1971). Mechanochemistry of inorganic solids. Russian Chem. Rev. 40, 847-859. doi: 10.1070/RC1971v040n10ABEH001977

Boldyreva, E. (2013). Mechanochemistry of inorganic and organic systems: what is similar, what is different? Chem. Soc. Rev. 42, 7719-7738. doi: $10.1039 / \mathrm{c} 3 \operatorname{cs} 60052 \mathrm{a}$

Boldyreva, E. (2016). Non-ambient conditions in the investigation and manufacturing of drug forms. Curr. Pharm. Des. 22, 4981-5000. doi: $10.2174 / 1381612822666160804093120$

Bolm, C., and Hernandez, J. G. (2019). Mechanochemistry of gaseous reactants. Angew. Chem. Int. Ed. 58, 3285-3299. doi: 10.1002/anie.201810902

Borhade, A. V., Uphade, B. K., and Gadhave, A. G. (2016). Calcinized eggshell: an environmentally benign green catalyst for synthesis of 2arylbenzothiazole derivatives. Res. Chem. Intermediat. 42, 6301-6311. doi: 10.1007/s11164-016-2463-5

Braga, D., Maini, L., and Grepioni, F. (2013). Mechanochemical preparation of co-crystals. Chem. Soc. Rev. 42, 7638-7648. doi: 10.1039/c3cs60014a

Burley, R. W., and Vadehra, D. V. (1989). The Avian Egg: Chemistry and Biology. New York, NY: Wiley-Interscience Publications.

Butyagin, P. Y. (1971). Kinetics and nature of mechanochemical reactions. Russian Chem. Rev. 63, 901-915. doi: 10.1070/RC1971v040n11ABEH001982

Butyagin, P. Y. (1994). Problems in mechanochemistry and prospects for its development. Russian Chem. Rev. 63, 965-976. doi: 10.1070/RC1994v063n12ABEH000129

Bychkov, A., Podgorbunskikh, E., Bychkova, E., and Lomovsky, O. (2019). Current achievements in the mechanically pretreated conversion of plant biomass. Biotechnol. Bioeng. 116, 1231-1244. doi: 10.1002/bit.26925

Cagnetta, G., Robertson, J., Huang, J., Zhang, K. L., and Yu, G. (2016). Mechanochemical destruction of halogenated organic pollutants: a critical review. J. Hazard. Mater. 313, 85-102. doi: 10.1016/j.jhazmat.2016.03.076

Cartwright, J. H. E., Checa, A. G., Gale, J. D., Gebauer, D., and Sainz-Diaz, C. I. (2012). Calcium carbonate polyamorphism and its role in biomineralization: how many amorphous calcium carbonates are there? Angew. Chem. Int. Ed. 51, 11960-11970. doi: 10.1002/anie.201203125

Carvalho, J., Araujo, J., and Castro, F. (2011). Alternative low-cost adsorbent for water and wastewater decontamination derived from eggshell waste: an overview. Waste Biomass Valorization 2, 157-167. doi: 10.1007/s12649-010-9058-y

Cestari, F., Chemello, G., Galotta, A., and Sglavo, V. M. (2020). Low-temperature synthesis of nanometric apatite from biogenic sources. Ceramics Int. 46, 23526-23533. doi: 10.1016/j.ceramint.2020.06.123

Cherdchom, S., Rattanaphan, T., and Chanadee, T. (2019). Calcium titanate from food waste: combustion synthesis, sintering, characterization, and properties. Adv. Mater. Sci. Eng. 2019:9639016. doi: 10.1155/2019/9639016

Chowdhury, S. D. (1990). Shell membrane-protein system in relation to lathyrogen toxicity and copper deficiency. Worlds Poult. Sci. J. 46, 153-169. doi: 10.1079/WPS19900018

Colacino, E., Porcheddu, A., Halasz, I., Charnay, C., Delogu, F., Guerra, R., et al. (2018). Mechanochemistry for "no solvent, no base" preparation of hydantoinbased active pharmaceutical ingredients: nitrofurantoin and dantrolene. Green Chem. 20, 2973-2977. doi: 10.1039/C8GC01345D

Cordeiro, C. M. M., and Hincke, M. T. (2011). Recent patents on eggshell: shell and membrane applications. Recent Patents Food Nutr. Agric. 3, 1-8. doi: $10.2174 / 2212798411103010001$

Cui, T.-L., He, J.-Y., and Liu, C.-S. (2020). High electrochemical performance carbon nanofibers with hierarchical structure derived from metal-organic framework with natural eggshell membranes. J. Colloid Interface Sci. 560, 811-816. doi: 10.1016/j.jcis.2019.11.008

da Silva, R. J., Lima, R., de Oliveira, M. C. A., Alcaraz-Espinoza, J. J., De Melo, C. P., and De Oliveira, H. P. (2020). Supercapacitors based on (carbon nanostructure)/PEDOT/(eggshell membrane) electrodes. J. Electroanal. Chem. 856:113658. doi: 10.1016/j.jelechem.2019.113658

da Silveira Pinto, L. S., and de Souza, M. V. N. (2019). Eggshell, a promising waste in organic reactions. Lett. Org. Chem. 16, 851-859. doi: 10.2174/1570178616666190123115432

Dawson, M. (2003). Wound Healing Composition and Method for Use Thereof. USA Patent Application US6541447B1. Washington, DC: U.S. Patent and Trademark Office.
De Oliveira, P. F., Michalchuk, A. A., Marquardt, J., Feiler, T., Prinz, C., Torresi, R. M., et al. (2020a). Investigating the role of reducing agents on mechanosynthesis of Au nanoparticles. CrystEngComm 22, 6261-6267. doi: 10.1039/D0CE00826E

De Oliveira, P. F. M., Torresi, R. M., Emmerling, F., and Camargo, P. H. C. (2020b). Challenges and opportunities in the bottom-up mechanochemical synthesis of noble metal nanoparticles. J. Mater. Chem. A 8, 16114-16141. doi: 10.1039/D0TA05183G

Declerck, V., Nun, P., Martinez, J., and Lamaty, F. (2009). Solvent-free synthesis of peptides. Angew. Chem. Int. Ed. 48, 9318-9321. doi: 10.1002/anie.200903510

Ding, Q., Kang, Z. W., Cao, L. P., Lin, M. S., Lin, H. T., and Yang, D. P. (2020). Conversion of waste eggshell into difunctional $\mathrm{Au} / \mathrm{CaCO}_{3}$ nanocomposite for 4-nitrophenol electrochemical detection and catalytic reduction. Appl. Surf. Sci. 510:145526. doi: 10.1016/j.apsusc.2020.145526

Dombre, C., Guyot, N., Moreau, T., Monget, P., Da Silva, M., Gautron, J., et al. (2017). Egg serpins: the chicken and/or the egg dilemma. Semin. Cell Dev. Biol. 62, 120-132. doi: 10.1016/j.semcdb.2016.08.019

Dubourdieu, D. (2019). "Egg shell membranes for veterinary uses," in Nutraceuticals in Veterinary Medicine, eds R. C. Gupta, A. Srivastava, and R. Lall (Cham: Springer), 227-233.

El-Shibiny, S., Abd El-Gawad, M. A. M., Assem, F. M., and El-Sayed, S. M. (2018). The use of nano-sized eggshell powder for calcium fortification of cow's and buffalo's milk yogurts. Acta Sci. Polonorum Technol. Aliment. 17, 37-49. doi: 10.17306/J.AFS.2018.0541

El-Zeftawy, M., Ali, S. A., Salah, S., and Hafez, H. S. (2020). The functional nutritional and regulatory activities of calcium supplementation from eggshell for obesity disorders management. J. Food Biochem. 44:e13313. doi: $10.1111 /$ jfbc. 13313

Fan, S., Xu, L. H., Kang, T. J., and Kim, H. T. (2017). Application of eggshell as catalyst for low rank coal gasification: experimental and kinetic studies. $J$. Energy Inst. 90, 696-703. doi: 10.1016/j.joei.2016.07.008

Farjah, G. H., Mohammdzadeh, S., and Javanmard, M. Z. (2020). The effect of lycopene in egg shell membrane guidance channel on sciatic nerve regeneration in rats. Iran. J. Basic Med. Sci. 23, 527-533. doi: 10.22038/ijbms.2020.40228.9525

Ferro, A. C., and Guedes, M. (2019). Mechanochemical synthesis of hydroxyapatite using cuttlefish bone and chicken eggshell as calcium precursors. Mater. Sci. Eng. C 97, 124-140. doi: 10.1016/j.msec.2018.11.083

Florencio-Silva, R., Sasso, G. R. D., Sasso-Cerri, E., Simoes, M. J., and Cerri, P. S. (2015). Biology of bone tissue: structure, function, and factors that influence bone cells. Biomed. Res. Int. 2015:421746. doi: 10.1155/2015/421746

Foruzin, L. J., Rezvani, Z., and Habibi, B. (2020). New ternary-component layered double hydroxide as a low-cost and efficient electrocatalyst for water oxidation: NiCaFe-LDH from eggshell bio-waste. Appl. Clay Sci. 188:105511. doi: 10.1016/j.clay.2020.105511

Gao, Y., and Xu, C. L. (2012). Synthesis of dimethyl carbonate over waste eggshell catalyst. Catal. Today 190, 107-111. doi: 10.1016/j.cattod.2011.12.004

García, M. A. L. N., and González, A. A. (2020). Method and Composition for Hydrolyzing Eggshell Membrane. U.S. Patent Application No. 16/629,549. Washington, DC: U.S. Patent and Trademark Office.

Gardner, C. R., Walsh, C. T., and Almarsson, O. (2004). Drugs as materials: valuing physical form in drug discovery. Nat. Rev. Drug Discov. 3, 926-934. doi: $10.1038 / \mathrm{nrd} 1550$

Gautron, J., Guyot, N., Brionne, A., and Rehault-Godbert, S. (2019). "Bioactive minor egg components," in Eggs as Functional Foods and Nutraceuticals for Human Health, ed J. Wu (London: RSC), 259-284.

Gil-Quintana, E., Fenaux, M., Nuez, M. L., Molero, A., and Aguirre, A. (2018). Short-term effects of ovomet $\AA$, egg-shell membrane. Joint pain: a double-blind and placebo study. J. Osteopor. Phys. Act. 6:1000211. doi: 10.4172/2329-9509.1000211

Girelli, A. M., Astolfi, M. L., and Scuto, F. R. (2020). Agro-industrial wastes as potential carriers for enzyme immobilization: a review. Chemosphere 244:125368. doi: 10.1016/j.chemosphere.2019.125368

Gollakota, A. R. K., Volli, V., and Shu, C.-M. (2019). Transesterification of waste cooking oil using pyrolysis residue supported eggshell catalyst. Sci. Total Environ. 661, 316-325. doi: 10.1016/j.scitotenv.2019.01.165

Gomollón-Bel, F. (2019). Ten chemical innovations that will change our world. Chem. Int. 41, 12-17. doi: 10.1515/ci-2019-0203 
Grant, A. M., Anderson, F. H., Avenell, A., Campbell, M. K., Cooper, C., Donaldson, C., et al. (2005). Oral vitamin D3 and calcium for secondary prevention of low-trauma fractures in elderly people (Randomised evaluation of calcium or vitamin D, RECORD): a randomised placebocontrolled trial. Lancet 365, 1621-1628. doi: 10.1016/S0140-6736(05) 63013-9

Groote, R., Jakobs, R. T. M., and Sijbesma, R. P. (2013). Mechanocatalysis: forcing latent catalysts into action. Polym. Chem. 4, 4846-4859. doi: $10.1039 / \mathrm{c} 3$ py00071k

Guarderas, F., Leavell, Y., Sengupta, T., Zhukova, M., and Megraw, T. L. (2016). Assessment of chicken-egg membrane as a dressing for wound healing. Adv. Skin Wound Care 29, 131-134. doi: 10.1097/01.ASW.0000480359.58866.e9

Guo, X. Y., Xiang, D., Duan, G. H., and Mou, P. (2010). A review of mechanochemistry applications in waste management. Waste Manage. 30, 4-10. doi: 10.1016/j.wasman.2009.08.017

Guo, Y. L., Sun, Y. J., Yang, D. P., Dai, J. J., Liu, Z. L., Chen, Y. S., et al. (2020). Biogenic $\mathrm{Pt} / \mathrm{CaCO}_{3}$ nanocomposite as a robust catalyst toward benzene oxidation. ACS Appl. Mater. Interfaces 12, 2469-2480. doi: 10.1021/acsami.9b18490

Guo, Y. L., Yang, D. P., Liu, M. H., Zhang, X. Y., Chen, Y. S., Huang, J. L., et al. (2019). Enhanced catalytic benzene oxidation over a novel waste-derived Ag/eggshell catalyst. J. Mater. Chem. A 7, 8832-8844. doi: 10.1039/C8TA10822F

Gupta, A. R., and Rathod, V. K. (2018). Waste cooking oil and waste chicken eggshells derived solid base catalyst for the biodiesel production: optimization and kinetics. Waste Manage. 79, 169-178. doi: 10.1016/j.wasman.2018.07.022

Guru, P. S., and Dash, S. (2014). Sorption on eggshell waste-a review on ultrastructure, biomineralization and other applications. Adv. Colloid Interface Sci. 209, 49-67. doi: 10.1016/j.cis.2013.12.013

Gutman, E. M. (1998). Mechanochemistry of Materials. Beer-Sheva: Materials Engineering Dept.

Hamada, H. M., Tayeh, B. A., Al-Attar, A., Yahaya, F. M., Muthusamy, K., M., et al. (2020). The present state of the use of eggshell powder in concrete: a review. J. Build. Eng. 32:101583. doi: 10.1016/j.jobe.2020.101583

Hart, A. (2020). Mini-review of waste shell-derived materials' applications. Waste Manage. Res. 38, 514-527. doi: 10.1177/0734242X19897812

He, X., Yang, D.-P., Zhang, X., Liu, M., Rang, Z., Lin, C., et al. (2019). Waste eggshell membrane-templated $\mathrm{CuO}-\mathrm{ZnO}$ nanocomposites with enhanced adsorption, catalysis and antibacterial properties for water purification. Chem. Eng. J. 369, 621-633. doi: 10.1016/j.cej.2019.03.047

He, W., Yang, S., and Zhang, G. (2016). Recent studies on eggshell as adsorption material. Trans. Chin. Soc. Agric. Eng. 32, 297-303.

Heinicke, G. (1984). Tribochemistry. Berlin: Akademie-Verlag, Berlin.

Hernández, J. G., Halasz, I., Crawford, D. E., Krupička, M., Baláž, M., André, V., et al. (2020). European research in focus: mechanochemistry for sustainable industry (COST action MechSustInd). Eur. J. Org. Chem. 2020, 8-9. doi: 10.1002/ejoc.201901718

Hewlings, S., Kalman, D., and Schneider, L. V. (2019). A randomized, doubleblind, placebo-controlled, prospective clinical trial evaluating water-soluble chicken eggshell membrane for improvement in joint health in adults with knee osteoarthritis. J. Med. Food 22, 875-884. doi: 10.1089/jmf.2019.0068

Hincke, M. T., Da Silva, M., Guyot, N., Gautron, J., Mckee, M. D., GuabirabaBrito, R., et al. (2019). Dynamics of structural barriers and innate immune components during incubation of the avian egg: critical interplay between autonomous embryonic development and maternal anticipation. J. Innate Immun. 11, 111-124. doi: 10.1159/000493719

Hincke, M. T., Gautron, J., Panheleux, M., Garcia-Ruiz, J., Mckee, M. D., and Nys, Y. (2000). Identification and localization of lysozyme as a component of eggshell membranes and eggshell matrix. Matrix Biol. 19, 443-453. doi: 10.1016/S0945-053X(00)00095-0

Hincke, M. T., Nys, Y., Gautron, J., Mann, K., Rodriguez-Navarro, A. B., and Mckee, M. D. (2012). The eggshell: structure, composition and mineralization. Front. Biosci. 17, 1266-1280. doi: 10.2741/3985

Hincke, M. T. (2019). "Value-added uses of eggshell and eggshell membranes," in Eggs as Functional Foods and Nutraceuticals for Human Health, ed M. T. Hincke (London: RSC), 359-397.

Holkar, C. R., Jadhav, A. J., Pinjari, D. V., Mahamuni, N. M., and Pandit, A. B. (2016). A critical review on textile wastewater treatments: possible approaches. J. Environ. Manage. 182, 351-366. doi: 10.1016/j.jenvman.2016. 07.090

Huang, X., Li, X., Ma, M. H., Cai, Y. Y., and Fu, X. (2020). Water Resistant Enhanced Wound Healing Film and Preparation Method Thereof. USA patent application US20200030385. Washington, DC: U.S. Patent and Trademark Office.

Hunton, P. (2005). Research on eggshell structure and quality: an historical overview. Revis. Bras. Ciencia Avicola 7, 67-71. doi: 10.1590/S1516-635X2005000200001

Huot, J., Ravnsbaek, D. B., Zhang, J., Cuevas, F., Latroche, M., and Jensen, T. R. (2013). Mechanochemical synthesis of hydrogen storage materials. Prog. Mater. Sci. 58, 30-75. doi: 10.1016/j.pmatsci.2012.07.001

Ingole, V. H., Vuherer, T., Maver, U., Vinchurkar, A., Ghule, A. V., and Kokol, V. (2020). Mechanical properties and cytotoxicity of differently structured nanocellulose-hydroxyapatite based composites for bone regeneration application. Nanomaterials 10:25. doi: 10.3390/nano10010025

Ino, T., Hattori, M., Yoshida, T., Hattori, S., Yoshimura, K., and Takahashi, K. (2006). Improved physical and biochemical features of a collagen membrane by conjugating with soluble egg shell membrane protein. Biosci. Biotechnol. Biochem. 70, 865-873. doi: 10.1271/bbb.70.865

Islam, M. K., Tusty, T. A., Akhand, A. A., and Ahsan, N. (2019). Human uptake of eggshell powder as an alternate source of calcium. Dhaka Univ. J. Pharm. Sci. 18, 249-255. doi: 10.3329/dujps.v18i2.44465

Jalili-Firoozinezhad, S., Filippi, M., Mohabatpour, F., Letourneur, D., and Scherberich, A. (2020). Chicken egg white: hatching of a new old biomaterial. Mater. Today 40, 193-214. doi: 10.1016/j.mattod.2020.05.022

James, S. L., Adams, C. J., Bolm, C., Braga, D., Collier, P., Friščić, T., et al. (2012). Mechanochemistry: opportunities for new and cleaner synthesis. Chem. Soc. Rev. 41, 413-447. doi: 10.1039/C1CS15171A

Jayasree, R., Madhumathi, K., Rana, D., Ramalingam, M., Nankar, R. P., Doble, M., et al. (2018). Development of egg shell derived carbonated apatite nanocarrier system for drug delivery. J. Nanosci. Nanotechnol. 18, 2318-2324. doi: 10.1166/jnn.2018.14377

Jensen, G. S., Shah, B., Holtz, R., Patel, A., and Lo, D. C. (2016). Reduction of facial wrinkles by hydrolyzed water-soluble egg membrane associated with reduction of free radical stress and support of matrix production by dermal fibroblasts. Clin. Cosmetic Invest. Dermatol. 9, 357-365. doi: 10.2147/CCID.S111999

Jun, H. J., Oh, K.-H., Yoo, J., Han, W.-G., Chang, J., Jung, H. H., et al. (2014). A new patch material for tympanic membrane perforation by trauma: the membrane of a hen egg shell. Acta Otolaryngol. 134, 250-254. doi: 10.3109/00016489.2013.857784

Karuppiah, D., Palanisamy, R., Ponnaiah, A., Liu, W. R., Huang, C. H., Rengapillai, S., et al. (2020). Eggshell-membrane-derived carbon coated on Li2FeSiO4 cathode material for Li-Ion batteries. Energies 13:786. doi: 10.3390/en13040786

Kattimani, V., Lingamaneni, K. P., Yalamanchili, S., and Mupparapu, M. (2019a). Use of eggshell-derived nano-hydroxyapatite as novel bone graft substituteA randomized controlled clinical study. J. Biomater. Appl. 34, 597-614. doi: $10.1177 / 0885328219863311$

Kattimani, V. S., and Lingamaneni, K. P. (2019). Natural bioceramics: our experience with changing perspectives in the reconstruction of maxillofacial skeleton. J. Korean Assoc. Oral. Maxillofacial Surg. 45, 34-42. doi: 10.5125/jkaoms.2019.45.1.34

Kattimani, V. S., Lingamaneni, K. P., Kreedapathi, G. E., and Kattappagari, K. K. (2019b). Socket preservation using eggshell-derived nanohydroxyapatite with platelet-rich fibrin as a barrier membrane: a new technique. J. Korean Assoc. Oral Maxillofacial Surg. 45, 332-342. doi: 10.5125/jkaoms.2019.45.6.332

Kaweewong, K., Garnjanagoonchorn, W., Jirapakkul, W., and Roytrakul, S. (2013). Solubilization and identification of hen eggshell membrane proteins during different times of chicken embryo development using the proteomic approach. Protein J. 32, 297-308. doi: 10.1007/s10930-013-9487-0

Kenny, E., Schmidt, R., Suso, H. P., and Barham, P. (2018). Dry Biocompatible Disintegratable Films for Delivering Particulate Egg Shell Membrane to a Wound. USA Patent Application US20180325740A1. Washington, DC: U.S. Patent and Trademark Office.

Kerru, N., Gummidi, L., Bhaskaruni, S. H. S., Maddila, S. N., and Jonnalagadda, S. B. (2020). One-pot green synthesis of novel 5,10-dihydro-1H-pyrazolo 1,2-b phthalazine derivatives with eco-friendly biodegradable eggshell 
powder as efficacious catalyst. Res. Chem. Intermediat. 46, 3067-3083. doi: 10.1007/s11164-020-04135-6

Khairol, N. F., Sapawe, N., and Danish, M. (2019a). Effective photocatalytic removal of different dye stuffs using $\mathrm{ZnO} / \mathrm{CuO}$-incorporated onto eggshell templating. Mater. Today Proc. 19, 1255-1260. doi: 10.1016/j.matpr.2019.11.130

Khairol, N. F., Sapawe, N., and Danish, M. (2019b). Excellent performance integrated both adsorption and photocatalytic reaction toward degradation of congo red by CuO/eggshell. Mater. Today Proc. 19, 1340-1345. doi: 10.1016/j.matpr.2019.11.147

King'ori, A. M. (2011). A review of the uses of poultry eggshells and shell membranes. Int. J. Poult. Sci. 10, 908-912. doi: 10.3923/ijps.2011.908.912

Kirubakaran, M., and Selvan, V. A. M. (2018). Eggshell as heterogeneous catalyst for synthesis of biodiesel from high free fatty acid chicken fat and its working characteristics on a CI engine. J. Environ. Chem. Eng. 6, 4490-4503. doi: 10.1016/j.jece.2018.06.027

Kiselioviene, S., Baniukaitiene, O., Harkavenko, V., Babenko, N. A., and Liesiene, J. (2016). Cellulose hydrogel sheets for wound dressings. Cell. Chem. Technol. 50, 915-923.

Konwar, M., Chetia, M., and Sarma, D. (2019). A low-cost, well-designed catalytic system derived from household waste "Egg Shell": applications in organic transformations. Top. Curr. Chem. 377:6. doi: 10.1007/s41061-018-0230-3

Konygin, G. N., Strelkov, N. S., Rybin, D. S., Pozdeev, V. V., Yelsukov, E. P., Sharafutdinova, D. R., et al. (2014). Method for Producing Mechanically Activated Amorphous and Amorphocrystalline Compounds of Gluconic Acid Calcium Salt. USA Patent Application US8877810B2. Washington, DC: U.S. Patent and Trademark Office.

Krishnan, P. D., Banas, D., Durai, R. D., Kabanov, D., Hosnedlova, B., Kepinska, M., et al. (2020). Silver nanomaterials for wound dressing applications. Pharmaceutics 12:821. doi: 10.3390/pharmaceutics12090821

Kulshreshtha, G., Ahmed, T. A. E., Wu, L., Diep, T., and Hincke, M. T. (2020). A novel eco-friendly green approach to produce particalized eggshell membrane (PEM) for skin health applications. Biomater. Sci. 8, 5346-5361. doi: 10.1039/D0BM01110J

Kumar, D., and Ali, A. (2012). Nanocrystalline K-CaO for the transesterification of a variety of feedstocks: structure, kinetics and catalytic properties. Biomass Bioenergy 46, 459-468. doi: 10.1016/j.biombioe.2012.06.040

Kumar, S., Dwivedi, S. P., and Dwivedi, V. K. (2020). Synthesis and characterization of ball-milled eggshell and $\mathrm{Al} 2 \mathrm{O} 3$ reinforced hybrid green composite material. J. Metals Mater. Miner. 30, 67-75. doi: $10.14456 / j m m m .2020 .22$

Kuruoglu, E. (2017). Using eggshell membrane in the fresh cadaveric cow brain for brain protection. Arch. Med. 1:23. doi: 10.21767/2471-9633.100022

Laca, A., Laca, A., and Díaz, M. (2017). Eggshell waste as catalyst: a review. J. Environ. Manage. 197, 351-359. doi: 10.1016/j.jenvman.2017.03.088

Laranjeira, M. S., Fernandes, M. H., and Monteiro, F. J. (2010). Innovative macroporous granules of nanostructured-hydroxyapatite agglomerates: bioactivity and osteoblast-like cell behaviour. J. Biomed. Mater. Res. A 95a, 891-900. doi: 10.1002/jbm.a.32916

Leach, R. M. (1982). Biochemistry of the organic matrix of the eggshell. Poult. Sci. 61, 2040-2047. doi: 10.3382/ps.0612040

Li, J., Zhai, D., Lv, F., Yu, Q., Ma, H., Yin, J., et al. (2016). Preparation of coppercontaining bioactive glass/eggshell membrane nanocomposites for improving angiogenesis, antibacterial activity and wound healing. Acta Biomater. 36, 254-266. doi: 10.1016/j.actbio.2016.03.011

Li, M. Y., Yang, J. K., Liang, S., Hou, H. J., Hu, J. P., Liu, B. C., et al. (2019a). Review on clean recovery of discarded/spent lead-acid battery and trends of recycled products. J. Power Sources 436:226853. doi: 10.1016/j.jpowsour.2019.226853

Li, N., Niu, L. N., Qi, Y. P., Yiu, C. K. Y., Ryou, H., Arola, D. D., et al. (2011). Subtleties of biomineralisation revealed by manipulation of the eggshell membrane. Biomaterials 32, 8743-8752. doi: 10.1016/j.biomaterials.2011.08.007

Li, X., Cai, Z., Ahn, D. U., and Huang, X. (2019b). Development of an antibacterial nanobiomaterial for wound-care based on the absorption of AgNPs on the eggshell membrane. Colloids Surf. B Biointerfaces 183:110449. doi: 10.1016/j.colsurfb.2019.110449

Li, X., Ma, M., Ahn, D. U., and Huang, X. (2019c). Preparation and characterization of novel eggshell membrane-chitosan blend films for potential wound-care dressing: from waste to medicinal products. Int. J. Biol. Macromol. 123, 477-484. doi: 10.1016/j.ijbiomac.2018.10.215

Li, Y., Zhou, J., Fan, Y., Ye, Y., and Tang, B. (2017). Preparation of environmentfriendly 3D eggshell membrane-supported anatase $\mathrm{TiO}_{2}$ as a reusable photocatalyst for degradation of organic dyes. Chem. Phys. Lett. 689, 142-147. doi: 10.1016/j.cplett.2017.10.019

Li, Z., Zhang, L., Amirkhiz, B. S., Tan, X., Xu, Z., Wang, H., et al. (2012). Carbonized chicken eggshell membranes with 3D architectures as highperformance electrode materials for supercapacitors. Adv. Energy Mater. 2, 431-437. doi: 10.1002/aenm.201100548

Li, Z. H., Yang, D. P., Chen, Y. S., Du, Z. Y., Guo, Y. L., Huang, J. L., et al. (2020). Waste eggshells to valuable $\mathrm{Co}_{3} \mathrm{O}_{4} / \mathrm{CaCO}_{3}$ materials as efficient catalysts for VOCs oxidation. Mol. Catal. 483:110766. doi: 10.1016/j.mcat.2020. 110766

Liang, M., Su, R., Qi, W., Zhang, Y., Huang, R., Yu, Y., et al. (2014). Reduction of hexavalent chromium using recyclable $\mathrm{Pt} / \mathrm{Pd}$ nanoparticles immobilized on procyanidin-grafted eggshell membrane. Ind. Eng. Chem. Res. 53, 13635-13643. doi: $10.1021 /$ ie5021552

Lima, D. S., and Perez-Lopez, O. W. (2020). Oxidative coupling of methane to light olefins using waste eggshell as catalyst. Inorg. Chem. Commun. 116:107928. doi: 10.1016/j.inoche.2020.107928

Liu, Q. Q., Chen, X. Y., Kang, Z. W., Zheng, C. H., and Yang, D. P. (2020a). Facile synthesis of eggshell membrane-templated $\mathrm{Au} / \mathrm{CeO}_{2} 3 \mathrm{D}$ nanocomposite networks for nonenzymatic electrochemical dopamine sensor. Nanoscale Res. Lett. 15:24. doi: 10.1186/s11671-019-3203-8

Liu, X. N., Shen, F., and Qi, X. H. (2019). Adsorption recovery of phosphate from aqueous solution by $\mathrm{CaO}$-biochar composites prepared from eggshell and rice straw. Sci. Total Environ. 666, 694-702. doi: 10.1016/j.scitotenv.2019.02.227

Liu, Y., Cai, Z., Ma, M., Sheng, L., and Huang, X. (2020b). Effect of eggshell membrane as porogen on the physicochemical structure and protease immobilization of chitosan-based macroparticles. Carbohydr. Polym. 242:116387. doi: 10.1016/j.carbpol.2020.116387

Lomovsky, O. I., and Boldyrev, V. V. (2006). Mechanochemistry and Ecological Problems. Novosibirsk: GPNTB Publisher.

Lu, S., Hummel, M., Gu, Z., Gu, Y., Cen, Z., Wei, L., et al. (2019). Trash to treasure: a novel chemical route to synthesis of $\mathrm{NiO} / \mathrm{C}$ for hydrogen production. Int. J. Hydrogen Energy 44, 16144-16153. doi: 10.1016/j.ijhydene.2019.04.191

Manique, M. C., Lacerda, L. V., Alves, A. K., and Bergmann, C. P. (2017). Biodiesel production using coal fly ash-derived sodalite as a heterogeneous catalyst. Fuel 190, 268-273. doi: 10.1016/j.fuel.2016.11.016

Marinkovic, D. M., Stankovic, M. V., Velickovic, A. V., Avramovic, J. M., Miladinovic, M. R., Stamenkovic, O. O., et al. (2016). Calcium oxide as a promising heterogeneous catalyst for biodiesel production: current state and perspectives. Renew. Sust. Energy Rev. 56, 1387-1408. doi: 10.1016/j.rser.2015.12.007

Marwaha, A., Rosha, P., Mohapatra, S. K., Mahla, S. K., and Dhir, A. (2018). Waste materials as potential catalysts for biodiesel production: current state and future scope. Fuel Process. Technol. 181, 175-186. doi: 10.1016/j.fuproc.2018.09.011

Mcnaught, A. D., and Wilkinson, A. (1997). IUPAC Compendium of Chemical Terminology ("The Golden Book"). Oxford: Blackwell Scientific Publication.

Meng, X., and Deng, D. (2016). Trash to treasure: waste eggshells used as reactor and template for synthesis of co9s 8 nanorod arrays on carbon fibers for energy storage. Chem. Mater. 28, 3897-3904. doi: 10.1021/acs.chemmater.6b01142

Meng, X., and Deng, D. (2019). Bio-inspired synthesis of 3-D network of NiO-Ni nanowires on carbonized eggshell membrane for lithium-ion batteries. Chem. Eng. Sci. 194, 134-141. doi: 10.1016/j.ces.2018.06.038

Minakshi, M., Higley, S., Baur, C., Mitchell, D. R. G., Jones, R. T., and Fichtner, M. (2019). Calcined chicken eggshell electrode for battery and supercapacitor applications. RSC Adv. 9, 26981-26995. doi: 10.1039/C9RA04289J

Minakshi, M., Mitchell, D. R. G., Jones, R. T., Pramanik, N. C., Jean-Fulcrand, A., and Garnweitner, G. (2020). A hybrid electrochemical energy storage device using sustainable electrode materials. Chemistryselect 5, 1597-1606. doi: 10.1002/slct.201904553

Minakshi, M., Visbal, H., Mitchell, D. R. G., and Fichtner, M. (2018). Biowaste chicken eggshells to store energy. Dalton Trans. 47, 16828-16834. doi: 10.1039/C8DT03252A

Mohammadi, S., Taher, M. A., Beitollahi, H., and Naghizadeh, M. (2019). Sensitive voltammetric determination of cadmium at a 
carbon nanotubes $/ \mathrm{Fe}_{3} \mathrm{O}_{4}$ /eggshell composites modified carbon paste electrode. Environ. Nanotechnol. Monitor. Manage. 12:100241. doi: 10.1016/j.enmm.2019.100241

Mohammadzadeh, L., Rahbarghazi, R., Salehi, R., and Mahkam, M. (2019). A novel egg-shell membrane based hybrid nanofibrous scaffold for cutaneous tissue engineering. J. Biol. Eng. 13:79. doi: 10.1186/s13036-019-0208-x

Mosaddegh, E. (2013). Ultrasonic-assisted preparation of nano eggshell powder: a novel catalyst in green and high efficient synthesis of 2-aminochromenes. Ultrason. Sonochem. 20, 1436-1441. doi: 10.1016/j.ultsonch.2013.04.008

Mosaddegh, E., and Hassankhani, A. (2014). Preparation and characterization of nano-CaO based on eggshell waste: novel and green catalytic approach to highly efficient synthesis of pyrano[4,3-b]pyrans. Chin. J. Catal. 35, 351-356. doi: 10.1016/S1872-2067(12)60755-4

Mosaddegh, E., Hassankhani, A., Pourahmadi, S., and Ghazanfari, D. (2013). Ball mill-assisted preparation of nano- $\mathrm{CaCO}_{3}$ as a novel and green catalyst-based eggshell waste: a green approach in the synthesis of pyrano[4,3-b]pyrans. Int. J. Green Nanotechnol. 5, 1-5. doi: 10.1177/1943089213507160

Motoji, H., To, M., Hidaka, K., and Matsuo, M. (2020). Vitamin C and eggshell membrane facilitate orthodontic tooth movement and induce histological changes in the periodontal tissue. J. Oral Biosci. 62, 80-87. doi: $10.1016 /$ j.job.2020.01.006

Munaron, L. (2006). Intracellular calcium, endothelial cells and angiogenesis. Recent Pat. Anticancer. Drug Discov. 1, 105-119. doi: 10.2174/157489206775246502

Munoz-Batista, M. J., Rodriguez-Padron, D., Puente-Santiago, A. R., Kubacka, A., Luque, R., and Fernandez-Garcia, M. (2018). Sunlight-driven hydrogen production using an annular flow photoreactor and g- $\mathrm{C}_{3} \mathrm{~N}_{4}$-based catalysts. Chemphotochem 2, 870-877. doi: 10.1002/cptc.201800064

Nakano, T., Ikawa, N. I., and Ozimek, L. (2003). Chemical composition of chicken eggshell and shell membranes. Poult. Sci. 82, 510-514. doi: 10.1093/ps/82.3.510

Nguyen, V. H., Lee, D. H., Baek, S. Y., and Kim, Y. H. (2018). Recycling different eggshell membranes for lithium-ion battery. Mater. Lett. 228, 504-508. doi: 10.1016/j.matlet.2018.06.081

Niu, M. F., Zhang, T. T., Wan, P., Du, M. X., Li, Y. H., and Fan, Y. W. (2017). Antibacterial activity of eggshell membrane enzymatic hydrolysate. Food Sci. Technol. 4.

Nys, Y., Gautron, J., Garcia-Ruiz, J. M., and Hincke, M. T. (2004). Avian eggshell mineralization: biochemical and functional characterization of matrix proteins. Comptes Rendus Palevol. 3, 549-562. doi: 10.1016/j.crpv.2004.08.002

Ohtsuka, Y., and Asami, K. (1997). Highly active catalysts from inexpensive raw materials for coal gasification. Catal. Today 39, 111-125. doi: 10.1016/S0920-5861(97)00093-X

Ononiwu, N. H., and Akinlabi, E. T. (2020). Effects of ball milling on particle size distribution and microstructure of eggshells for applications in metal matrix composites. Mater. Today-Proc. 26, 1049-1053. doi: 10.1016/j.matpr.2020.02.209

Onwubu, S. C., Mdluli, P. S., and Singh, S. (2019a). Evaluating the buffering and acid-resistant properties of eggshell-titanium dioxide composite against erosive acids. J. Appl. Biomater. Funct. Mater. 17:2280800018809914. doi: $10.1177 / 2280800018809914$

Onwubu, S. C., Mdluli, P. S., Singh, S., Madikizela, L., and Ngombane, Y. (2019b). Characterization and in vitro evaluation of an acid resistant nanosized dental eggshell-titanium dioxide material. Adv. Powder Technol. 30, 766-773. doi: 10.1016/j.apt.2019.01.005

Opris, H., Bran, S., Dinu, C., Baciut, M., Prodan, D. A., Mester, A., et al. (2020). Clinical applications of avian eggshell-derived hydroxyapatite. Bosnian J. Basic Med. Sci. 2, 430-437. doi: 10.17305/bjbms.2020.4888

Oulego, P., Laca, A., Calvo, S., and Diaz, M. (2020). Eggshell-supported catalysts for the advanced oxidation treatment of humic acid polluted wastewaters. Water 12:100. doi: 10.3390/w12010100

Palka, K. (2006). "Chemical and functional properties of food components," in Chemical and Functional Properties of Food Components, 3rd Edn, ed Z. E. Sikorski (Boca Raton: CRC Press), 15-28.

Panchal, M., Raghavendra, G. M., Rahul Reddy, A., Omprakash, M., and Ojha, S. (2020). Experimental investigation of mechanical and erosion behavior of eggshell nanoparticulate epoxy biocomposite. Polym. Polym. Compos. doi: $10.1177 / 0967391120943454$
Park, S., Choi, K. S., Lee, D., Kim, D., Lim, K. T., Lee, K. H., et al. (2016). Eggshell membrane: review and impact on engineering. Biosyst. Eng. 151, 446-463. doi: 10.1016/j.biosystemseng.2016.10.014

Park, S., Kim, T., Gwon, Y., Kim, S., Kim, D., Park, H. H., et al. (2019). Graphene-layered eggshell membrane as a flexible and functional scaffold for enhanced proliferation and differentiation of stem cells. ACS Appl. Bio Mater. 2, 4242-4248. doi: 10.1021/acsabm.9b00525

Patil, S., Jadhav, S. D., and Deshmukh, M. B. (2013). Calcined eggshell (CES): an efficient natural catalyst for knoevenagel condensation under aqueous condition. J. Chem. Sci. 125, 851-857. doi: 10.1007/s12039-013-0443-5

Pavlovic, S. M., Marinkovic, D. M., Kostic, M. D., Jankovic-Castvan, I. M., Mojovic, L. V., Stankovic, M. V., et al. (2020). A CaO/zeolite-based catalyst obtained from waste chicken eggshell and coal fly ash for biodiesel production. Fuel 267:117171. doi: 10.1016/j.fuel.2020.117171

Petkova, V., Kostova, B., Shopska, M., Kadinov, G., Baláž, M., and Baláž, P. (2017). Behavior of high-energy-milling-activated eggshells during thermal treatment. J. Therm. Anal. Calorim. 127, 615-623. doi: 10.1007/s10973-016-5710-5

Piras, C. C., Fernandez-Prieto, S., and De Borggraeve, W. M. (2019). Ball milling: a green technology for the preparation and functionalisation of nanocellulose derivatives. Nanoscale Adv. 1, 937-947. doi: 10.1039/C8NA00238J

Puertas-Bartolome, M., Vazquez-Lasa, B., and San Roman, J. (2018). Bioactive and bioadhesive catechol conjugated polymers for tissue regeneration. Polymers 10:768. doi: 10.3390/polym10070768

Puspitasari, P., Utomo, D. M., Zhorifah, H. F. N., Permanasari, A. A., and Hgayatri, R. W. (2020). Physicochemical determination of Calcium Carbonate (CaCO3) from chicken eggshell. Key Eng. Mater. 840, 478-483. doi: 10.4028/www.scientific.net/KEM.840.478

Puspitasari, P., Yuwanda, V., Sukarni, and Dika, J. W. (2019). The properties of eggshell powders with the variation of sintering duration. IOP Conf. Series Mat. Sci. Eng. 515:12104. doi: 10.1088/1757-899x/515/1/012104

Raheem, A., Liu, H., Ji, G. Z., and Zhao, M. (2019). Gasification of lipid-extracted microalgae biomass promoted by waste eggshell as $\mathrm{CaO}$ catalyst. Algal Res. Biomass Biofuels Bioprod. 42:101601. doi: 10.1016/j.algal.2019.101601

Rams-Baron, M., Jachowicz, R., Boldyreva, E. V., Zhou, D., Jamroz, W., and Paluch, M. (2018). Amorphous Drugs. New York, NY: pringer International Publishing.

Raz, P. G., Biswas, S., Roy, T., Ghosh, S., Majumder, D., Basak, P., et al. (2019). Sonication assisted hierarchical decoration of Ag-NP on zinc oxide nanoflower impregnated eggshell membrane: evaluation of antibacterial activity and in vitro cytocompatibility. Acs Sust. Chem. Eng. 7, 13717-13733. doi: 10.1021/acssuschemeng.9b01185

Reid, I. R., and Bolland, M. J. (2020). Calcium and/or vitamin D supplementation for the prevention of fragility fractures: who needs it? Nutrients 12:1011. doi: 10.3390/nu12041011

Reid, I. R., Bristow, S. M., and Bolland, M. J. (2015). Calcium supplements: benefits and risks. J. Intern. Med. 278, 354-368. doi: 10.1111/joim. 12394

Rodriguez-Navarro, A. B., Yebra, A., Nys, Y., Jimenez-Lopez, C., and GarciaRuiz, J. M. (2007). Analysis of avian eggshell microstructure using X-ray area detectors. Eur. J. Mineral. 19, 391-398. doi: 10.1127/0935-1221/2007/0019-1724

Rodriguez-Padron, D., Luque, R., and Munoz-Batista, M. J. (2020). Wastederived materials: opportunities in photocatalysis. Top. Curr. Chem. 378:3. doi: 10.1007/978-3-030-49492-6_1

Rodriguez-Padron, D., Puente-Santiago, A. R., Balu, A. M., Munoz-Batista, M. J., and Luque, R. (2019). Environmental catalysis: present and future. ChemCatChem 11, 18-38. doi: 10.1002/cctc.201801248

Rogachev, A. S. (2019). Mechanical activation of heterogeneous exothermic reactions in powder mixtures. Russian Chem. Rev. 88, 875-900. doi: 10.1070/RCR4884

Roopavath, U. K., Sah, M. K., Panigrahi, B. B., and Rath, S. N. (2019). Mechanochemically synthesized phase stable and biocompatible beta-tricalcium phosphate from avian eggshell for the development of tissue ingrowth system. Ceram. Int. 45, 12910-12919. doi: 10.1016/j.ceramint.2019.03.217

Rose, M. L. H., and Hincke, M. T. (2009). Protein constituents of the eggshell: eggshell-specific matrix proteins. Cell. Mol. Life Sci. 66, 2707-2719. doi: 10.1007/s00018-009-0046-y 
Rovensky, J., Stancikova, M., Masaryk, P., Svik, K., and Istok, R. (2003). Eggshell calcium in the prevention and treatment of osteoporosis. Int. J. Clin. Pharmacol. Res. 23, 83-92.

Ruff, K. J., Morrison, D., Duncan, S. A., Back, M., Aydogan, C., and Theodosakis, J. (2018). Beneficial effects of natural eggshell membrane versus placebo in exercise-induced joint pain, stiffness, and cartilage turnover in healthy, postmenopausal women. Clin. Interv. Aging 13, 285-295. doi: 10.2147/CIA.S153782

Rybin, D. S., Konygin, G. N., Porsev, V. E., Yelsukov, E. P., Arsentyeva, I. P., and Boldyrev, V. V. (2014). Deformation-induced structural transformations in molecular crystals. Acta Phys. Polonica A 126, 1014-1018. doi: 10.12693/APhysPolA.126.1014

Rybin, D. S., Konygin, G. N., Arsentyeva, I. P., and Sharafutdinova, D. R. (2018). Formation of nanostructures in mechanoactivated molecular crystals. Chem. Phys. Mesosc. 20, 558-562. Available online at: http://udman.ru/ru/book/cpm/ 2018/4/558_Rybin_Konygin_Arsentyeva_Sharafutdinova.pdf

Sah, M. K., and Rath, S. N. (2016). Soluble eggshell membrane: a natural protein to improve the properties of biomaterials used for tissue engineering applications. Mater. Sci. Eng. C 67, 807-821. doi: 10.1016/j.msec.2016.05.005

Sajadi, S. M., Kolo, K., Abdullah, S. M., Hamad, S. M., Khalid, H. S., and Yassein, A. T. (2018). Green synthesis of highly recyclable $\mathrm{CuO} /$ eggshell nanocomposite to efficient removal of aromatic containing compounds and reduction of 4-nitrophenol at room temperature. Surf. Interfaces 13, 205-215. doi: 10.1016/j.surfin.2018.08.006

Salah, M., Kataia, M. M., Kataia, E. M., El Din, E. A., and Essa, M. E. (2018). Evaluation of eggshell powder as an experimental direct pulp capping material. Future Dental J. 4, 160-164. doi: 10.1016/j.fdj.2018.05.008

Salaudeen, S. A., Tasnim, S. H., Heidari, M., Acharya, B., and Dutta, A. (2018). Eggshell as a potential $\mathrm{CO}_{2}$ sorbent in the calcium looping gasification of biomass. Waste Manage. 80, 274-284. doi: 10.1016/j.wasman.2018. 09.027

Salman, A. D., Juzsakova, T., Al-Mayyahi, M. A., Ibrahim, R. I., Abdullah, T. A., and Khader, E. H. (2020). Improvement of mechanical properties of Oil well cement by incorporate Nano-CaCO3 prepared from eggshell waste. IOP Conf. Series Mater. Sci. 765:12006. doi: 10.1088/1757-899X/765/1/012006

Sandri, G., Bonferoni, M. C., D’autilia, F., Rossi, S., Ferrari, F., Grisoli, P., et al. (2013). Wound dressings based on silver sulfadiazine solid lipid nanoparticles for tissue repairing. Eur. J. Pharm. Biopharm. 84, 84-90. doi: 10.1016/j.ejpb.2012.11.022

Sankar, M., Satav, S., and Manikandan, P. (2010). Transesterification of cyclic carbonates to dimethyl carbonate using solid oxide catalyst at ambient conditions: environmentally benign synthesis. ChemSusChem 3, 575-578. doi: $10.1002 /$ cssc. 201000038

Santos, K. O., Barbosa, R. C., Buriti, J. D. S., Bezerra Junior, A. G., Bacalhau De Sousa, W. J., Carvalho De Barros, S. M., et al. (2019). Thermal, chemical, biological and mechanical properties of chitosan films with powder of eggshell membrane for biomedical applications. J. Therm. Anal. Calorim. 136, 725-735. doi: 10.1007/s10973-018-7666-0

Saporito, F., Sandri, G., Bonferoni, M. C., Rossi, S., Boselli, C., Cornaglia, A. I., et al. (2018). Essential oil-loaded lipid nanoparticles for wound healing. Int. J. Nanomed. 13, 175-186. doi: 10.2147/IJN.S152529

Sari, Y. W., Listiani, E., Putri, S. Y., and Abidin, Z. (2020). Prospective of eggshell nanocalcium in improving biogas production from palm oil mill effluent. Waste Biomass Valorization 11, 4631-4638. doi: 10.1007/s12649-019-00786-8

Schmidt, R., Suso, H.-P., and Kenny, E. (2017). Micronized Eggshell Membrane Particles and the Use Thereof to Promote the Healing of Wounds. USA Patent Application US20170319629A1. Washington, DC: U.S. Patent and Trademark Office.

Seeharaj, P., Sripako, K., Promta, P., Detsri, E., and Vittayakorn, N. (2019). Facile and eco-friendly fabrication of hierarchical superhydrophobic coating from eggshell biowaste. Int. J. Appl. Ceramic Technol. 16, 1895-1903. doi: 10.1111/ijac. 13235

Selvakumari, J. C., Nishanthi, S. T., Dhanalakshmi, J., Ahila, M., and Padiyan, D. P. (2018). Bio-active synthesis of tin oxide nanoparticles using eggshell membrane for energy storage application. Appl. Surf. Sci. 441, 530-537. doi: 10.1016/j.apsusc.2018.02.043

Selvam, P. S. S., Chinnadurai, G. S., Ganesan, D., Perumal, P., and Kandan, V. (2020). Cadmium oxide-zinc oxide nanocomposites synthesized using waste eggshell membrane and its in-vitro assessments of the antimicrobial activities and minimum inhibitory concentration. J. Inorg. Organometallic Polym. Mater. doi: 10.1007/s10904-020-01688-2

Senthil, C., Vediappan, K., Nanthagopal, M., Kang, H. S., Santhoshkumar, P., Gnanamuthu, R., et al. (2019). Thermochemical conversion of eggshell as biological waste and its application as a functional material for lithium-ion batteries. Chem. Eng. J. 372, 765-773. doi: 10.1016/j.cej.2019.04.171

Šepelák, V., Düvel, A., Wilkening, M., Becker, K. D., and Heitjans, P. (2013). Mechanochemical reactions and syntheses of oxides. Chem. Soc. Rev. 42, 7507-7520. doi: 10.1039/c2cs35462d

Shafiei, S., Omidi, M., Nasehi, F., Golzar, H., Mohammadrezaei, D., Rad, M. R., et al. (2019). Egg shell-derived calcium phosphate/carbon dot nanofibrous scaffolds for bone tissue engineering: fabrication and characterization. Mater. Sci. Eng. C Mater. Biol. Appl. 100, 564-575. doi: 10.1016/j.msec.2019.03.003

Siemiradzka, W., Dolinska, B., and Ryszka, F. (2018). New sources of calcium (chicken eggshells, chelates) - preparation of raw material and tablets. Curr. Pharm. Biotechnol. 19, 566-572. doi: 10.2174/1389201019666180723103853

Silva, C. R., Babo, P. S., Gulino, M., Costa, L., Oliveira, J. M., Silva-Correia, J., et al. (2018). Injectable and tunable hyaluronic acid hydrogels releasing chemotactic and angiogenic growth factors for endodontic regeneration. Acta Biomater. 77, 155-171. doi: 10.1016/j.actbio.2018.07.035

Stadelman, W. J. (2000). "Egg and egg products," in Encyclopedia of Food Science and Technology, 2nd Edn. ed F. J. Francis (New York: John Wiley \& Sons), 593-599.

Stanković, M., Pavlović, S., Marinković, D., Tišma, M., Gabrovska, M., and Nikolova, D. (2020). "Solid green biodiesel catalysts derived from coal fly ash," in Renewable Energy: Resources, Challenges and Applications, eds M. Al Qubeissi, A. El-Kharouf, and H. S. Soyhan (London: IntechOpen), 1-24. doi: 10.5772/intechopen. 91703

Stolle, A., and Ranu, B. (2014). Ball milling towards green synthesis: applications, projects, challenges. $R$. Soc. Chem. doi: 10.1039/9781782621980

Supriyanto, N. S. W., Puspitasari, S. P., and Permanasari, A. A. (2019). Synthesis and characterization of $\mathrm{CaO} / \mathrm{CaCO} 3$ from quail eggshell waste by solid state reaction process. AIP Conf. Proc. 2120:40032. doi: 10.1063/1.5115670

Suryanarayana, C. (2019). Mechanical alloying: a novel technique to synthesize advanced materials. Research 2019:4219812. doi: 10.34133/2019/4219812

Tai, V., Leung, W., Grey, A., Reid, I. R., and Bolland, M. J. (2015). Calcium intake and bone mineral density: systematic review and meta-analysis. $B M J$ 351:h4183. doi: 10.1136/bmj.h4183

Taleb, M. A., Mamouni, R., Benomar, M. A., Bakka, A., Mouna, A., Taha, M. L., et al. (2017). Chemically treated eggshell wastes as a heterogeneous and ecofriendly catalyst for oximes preparation. J. Environ. Chem. Eng. 5, 1341-1348. doi: 10.1016/j.jece.2017.02.009

Tan, D., and García, F. (2019). Main group mechanochemistry: from curiosity to established protocols. Chem. Soc. Rev. 48, 2274-2292. doi: $10.1039 /$ C7CS00813A

Tan, Q. Y., and Li, J. H. (2015). Recycling metals from wastes: a novel application of mechanochemistry. Environ. Sci. Technol. 49, 5849-5861. doi: $10.1021 / \mathrm{es} 506016 \mathrm{w}$

Tan, Y. H., Abdullah, M. O., and Nolasco-Hipolito, C. (2015a). The potential of waste cooking oil-based biodiesel using heterogeneous catalyst derived from various calcined eggshells coupled with an emulsification technique: a review on the emission reduction and engine performance. Renew. Sust. Energy Rev. 47, 589-603. doi: 10.1016/j.rser.2015.03.048

Tan, Y. H., Abdullah, M. O., Nolasco-Hipolito, C., and Taufiq-Yap, Y. H. (2015b). Waste ostrich- and chicken-eggshells as heterogeneous base catalyst for biodiesel production from used cooking oil: catalyst characterization and biodiesel yield performance. Appl. Energy 160, 58-70. doi: 10.1016/j.apenergy.2015.09.023

Tkáčová, K. (1989). Mechanical Activation of Minerals. Bratislava: Veda.

Tong, J., Wang, W., Li, Q., Liu, F., Ma, W., Li, W., et al. (2017). Composite of FeCo alloy embedded in biocarbon derived from eggshell membrane with high performance for oxygen reduction reaction and supercapacitor. Electrochim. Acta 248, 388-396. doi: 10.1016/j.electacta.2017.07.125

Trakoolwannachai, V., Kheolamai, P., and Ummartyotin, S. (2019). Development of hydroxyapatite from eggshell waste and a chitosan-based composite: in vitro behavior of human osteoblast-like cell (Saos-2) cultures. Int. J. Biol. Macromol. 134, 557-564. doi: 10.1016/j.ijbiomac.2019.05.004 
Tummalapalli, M., Berthet, M., Verrier, B., Deopura, B. L., Alam, M. S., and Gupta, B. (2016). Composite wound dressings of pectin and gelatin with aloe vera and curcumin as bioactive agents. Int. J. Biol. Macromol. 82, 104-113. doi: 10.1016/j.ijbiomac.2015.10.087

van Hoten, H., Gunawarman, M. I. H., Mainil, A. K., and Bismantolo, P. (2018). Optimization of parameters for manufacture nanopowder bioceramics at machine pulverisette 6 by Taguchi and ANOVA method. J. Phys. 962:12010. doi: 10.1088/1742-6596/962/1/012010

Vanthana Sree, G., Nagaraaj, P., Kalanidhi, K., Aswathy, C. A., and Rajasekaran, P. (2020). Calcium oxide a sustainable photocatalyst derived from eggshell for efficient photo-degradation of organic pollutants. J. Clean. Prod. 270:122294. doi: 10.1016/j.jclepro.2020.122294

Verma, A. H., Kumar, T. S. S., Madhumathi, K., Rubaiya, Y., Ramalingan, M., and Doble, M. (2019). Curcumin releasing eggshell derived carbonated apatite nanocarriers for combined anti-cancer, anti-inflammatory and bone regenerative therapy. J. Nanosci. Nanotechnol. 19, 6872-6880. doi: 10.1166/jnn.2019.16640

Villarreal-Lucio, D. S., Armenta, J. L. R., Moreno, I. A. E., and GarciaAlamilla, R. (2019). Effect of surfactant in particle shape and thermal degradation of eggshell particles. Mater. Res. Ibero Am. J. Mater. 22:20180778. doi: 10.1590/1980-5373-MR-2018-0778

Vuong, T. T., Ronning, S. B., Ahmed, T. A. E., Brathagen, K., Host, V., Hincke, M. T., et al. (2018). Processed eggshell membrane powder regulates cellular functions and increase MMP-activity important in early wound healing processes. PLoS ONE 13:e0201975. doi: 10.1371/journal.pone.0201975

Vuong, T. T., Ronning, S. B., Suso, H.-P., Schmidt, R., Prydz, K., Lundstrom, M., et al. (2017). The extracellular matrix of eggshell displays anti-inflammatory activities through NF-kappa B in LPS-triggered human immune cells. J. Inflamm. Res. 10, 83-96. doi: 10.2147/JIR.S130974

Waheed, M., Butt, M. S., Shehzad, A., Adzahan, N. M., Shabbir, M. A., Suleria, H., et al. (2019). Eggshell calcium: a cheap alternative to expensive supplements. Trends Food Sci. Technol. 91, 219-230. doi: 10.1016/j.tifs.2019.07.021

Waheed, M., Yousaf, M., Shehzad, A., Inam-Ur-Raheem, M., Khan, M. K. I., Khan, M. R., et al. (2020). Channelling eggshell waste to valuable and utilizable products: a comprehensive review. Trends Food Sci. Technol. 106, 78-90. doi: $10.1016 /$ j.tifs.2020.10.009

Wong, M., Hendrix, M. J., Von Der Mark, K., Little, C., and Stern, R. (1984). Collagen in the egg shell membranes of the hen. Dev. Biol. 104, 28-36. doi: 10.1016/0012-1606(84)90033-2

Wu, X. C., Stroll, S. I., Lantigua, D., Suvarnapathaki, S., and Camci-Unal, G. (2019). Eggshell particle-reinforced hydrogels for bone tissue engineering: an orthogonal approach. Biomater. Sci. 7, 2675-2685. doi: 10.1039/C9BM00230H

Xie, Y., Yin, J., Zheng, J., Wang, L., Wu, J., Dresselhaus, M., et al. (2019). Synergistic cobalt sulfide/eggshell membrane carbon electrode. ACS Appl. Mater. Interfaces 11, 32244-32250. doi: 10.1021/acsami.9b06934

Yamauchi, K., Manabe, N., Matsumoto, Y., and Yamauchi, K.-E. (2013). Increased collagen accumulation in eggshell membrane after feeding with dietary wood charcoal powder and vinegar. Connect. Tissue Res. 54, 416-425. doi: 10.3109/03008207.2013.834895

Yan, S., Napiwocki, B., Xu, Y., Zhang, J., Zhang, X., Wang, X., et al. (2020a). Wavy small-diameter vascular graft made of eggshell membrane and thermoplastic polyurethane. Mater. Sci. Eng. C Mater. Biol. Appl. 107:110311. doi: 10.1016/j.msec.2019.110311

Yan, S., Xu, Y., Lin, Y.-J., Zhang, Z., Zhang, X., Yilmaz, G., et al. (2020b). Ethanol-lubricated expanded-polytetrafluoroethylene vascular grafts loaded with eggshell membrane extract and heparin for rapid endothelialization and anticoagulation. Appl. Surf. Sci. 511:145565. doi: 10.1016/j.apsusc.2020.145565

Yao, P., Bennett, D., Mafham, M., Lin, X., Chen, Z. M., Armitage, J., et al. (2019). Vitamin D and calcium for the prevention of fracture a systematic review and meta-analysis. JAMA Netw. Open 2:e1917789. doi: 10.1001/jamanetworkopen.2019.17789

Yoo, J., Park, K., Yoo, Y., Kim, J., Yang, H., and Shin, Y. (2014). Effects of egg shell membrane hydrolysates on anti-inflammatory, anti-wrinkle, anti- microbial activity and moisture-protection. Korean J. Food Sci. Anim. Resourc. 34, 26-32. doi: 10.5851/kosfa.2014.34.1.26

Yoosuk, B., Udomsap, P., Puttasawat, B., and Krasae, P. (2010). Modification of calcite by hydration-dehydration method for heterogeneous biodiesel production process: the effects of water on properties and activity. Chem. Eng. J. 162, 135-141. doi: 10.1016/j.cej.2010.05.013

Youseftabar-Miri, L. (2019). A clean and efficient synthesis of spiro 4H-pyranoxindole derivatives catalyzed by egg shell. Eurasian Chem. Commun. 1, 142-152. doi: 10.33945/SAMI/ECC.2019.2.3

Yu, H. J., Tang, Q. Q., Wu, J. H., Lin, Y. Z., Fan, L. Q., Huang, M. L., et al. (2012). Using eggshell membrane as a separator in supercapacitor. J. Power Sources 206, 463-468. doi: 10.1016/j.jpowsour.2012.01.116

Zhang, X., He, X., Kang, Z., Cui, M., Yang, D.-P., and Luque, R. (2019a). Waste eggshell-derived dual-functional cuo/zno/eggshell nanocomposites: (photo)catalytic reduction and bacterial inactivation. ACS Sust. Chem. Eng. 7, 15762-15771. doi: 10.1021/acssuschemeng.9b04083

Zhang, X., Huang, J., Kang, Z., Yang, D.-P., and Luque, R. (2020a). Eggshelltemplated synthesis of $\mathrm{PbS} / \mathrm{CaCO}_{3}$ nanocomposites for $\left(\mathrm{CO}_{3}^{-}\right)$-C-center dot mediated efficient degradation of tetracycline under solar light irradiation. Mol. Catal. 484:110786. doi: 10.1016/j.mcat.2020.110786

Zhang, X., Liu, M., Kang, Z., Wang, B., Wang, B., Jiang, F., et al. (2020b). NIR-triggered photocatalytic/photothermal/photodynamic water remediation using eggshell-derived $\mathrm{CaCO}_{3} / \mathrm{CuS}$ nanocomposites. Chem. Eng. J. 388:124304. doi: 10.1016/j.cej.2020.124304

Zhang, Y., He, J., Gao, Z., and Li, X. (2019b). Converting eggs to flexible, all-solid supercapacitors. Nano Energy 65:104045. doi: 10.1016/j.nanoen.2019.104045

Zhao, J. F., Syed, J. A., Wen, X. M., Lu, H. B., and Meng, X. K. (2019a). Green synthesis of FeS anchored carbon fibers using eggshell membrane as a bio-template for energy storage application. J. Alloys Compd. 777, 974-981. doi: 10.1016/j.jallcom.2018.10.202

Zhao, Q.-C., Zhao, J.-Y., Ahn, D. U., Jin, Y.-G., and Huang, X. (2019b). Separation and identification of highly efficient antioxidant peptides from eggshell membrane. Antioxidants 8:495. doi: 10.3390/antiox 8100495

Zhao, Y. H., and Chi, Y. J. (2009). Characterization of collagen from eggshell membrane. Biotechnology 8, 254-258. doi: 10.3923/biotech.2009.254.258

Zhong, S. L., Zhuang, J. Y., Yang, D. P., and Tang, D. P. (2017). Eggshell membrane-templated synthesis of 3D hierarchical porous Au networks for electrochemical nonenzymatic glucose sensor. Biosens. Bioelectron. 96, 26-32. doi: 10.1016/j.bios.2017.04.038

Zhou, J., Wang, S., Nie, F., Feng, L., Zhu, G., and Jiang, L. (2010). Elaborate architecture of the hierarchical hen's eggshell. Nano Res. 4, 171-179. doi: $10.1007 / \mathrm{s} 12274-010-0067-8$

Zhu, G. (2020). Egg membrane protein supplementation on rats after exhaustive exercise. Revis. Cien. Facult. Ciencias Vet. 30.

Zyryanov, V. V. (2008). Mechanochemical synthesis of complex oxides. Russian Chem. Rev. 77, 105-136. doi: 10.1070/RC2008v077n02ABEH0 03709

Conflict of Interest: DR was employed by the company Mezomax Inc., San-Francisco, CA, USA.

The remaining authors declare that the research was conducted in the absence of any commercial or financial relationships that could be construed as a potential conflict of interest.

Copyright (C) 2021 Baláž, Boldyreva, Rybin, Pavlović, Rodríguez-Padrón, Mudrinić and Luque. This is an open-access article distributed under the terms of the Creative Commons Attribution License (CC BY). The use, distribution or reproduction in other forums is permitted, provided the original author(s) and the copyright owner(s) are credited and that the original publication in this journal is cited, in accordance with accepted academic practice. No use, distribution or reproduction is permitted which does not comply with these terms. 


\section{LIST OF ABBREVIATIONS}

APD, ammonium phosphate dibasic

API, active pharmaceutical ingredient

4-AP, 4-aminophenol

$\mathrm{AV}$, Aloe vera

BG, bioactive glass

$\mathrm{BMD}$, bone mineral density

$\mathrm{CB}$, cuttlefish bone

CESM, carbonized eggshell membrane

$\mathrm{CN}$, carbon nanostructure

CNC, cellulose nanocrystal

CREMP, cysteine-rich eggshell membrane protein

CTGF, connective tissue growth factor

$2 \mathrm{D}$, two-dimensional

$3 \mathrm{D}$, three-dimensional

ePTFE, expanded polytetrafluorethylene

ES, eggshell

ESM, eggshell membrane

ESMP, eggshell membrane powder

ESP, eggshell powder

FTIR, Fourier-transform infra-red

GEM, graphene-layered ESM

HA, hydroxyapatite

HUVEC, human umbilical vein endothelial cells

IL- $1 \beta, \alpha$-interleukin- 1 beta

LFS, Lithium iron orthosilicate, $\mathrm{Li}_{2} \mathrm{FeSiO}_{4}$

MC, mineral composite

MS, mussel shell

NGC, nerve guidance channel

NIR, near infra-red

NP, nanoparticles

4-NP, 4-nitrophenol

$\mathrm{OM}$, organic matrix

OPG, osteoprotegerin

ORR, oxygen reduction reaction

PCL, poly ( $\varepsilon$-caprolactone)

PEM, particalized eggshell membrane

PEI, polyethyleneimine

PEP, processed eggshell membrane powder

PLA, poly(lactic) acid

PLD, pulsed laser deposition

PMN, polymorphonuclear

PTH, parathyroid hormone

PVA, polyvinyl alcohol

PVC, polyvinyl chloride

RANK, Receptor activator of nuclear factor kappa- $\beta$

RANKL, Receptor activator of nuclear factor kappa- $\beta$ ligand

SC, supercapacitor

SESM, soluble eggshell membrane

SF, silk fibroin

TCNF, (2,2,6,6-tetramethylpiperidin-1-yl)oxyl (TEMPO)-

oxidized cellulose nanofibrils

TEM, transition electron microscopy

TEMPO, (2,2,6,6-tetramethylpiperidin-1-yl)oxyl

TNF, tumor necrosis factor
VOC, volatile organic compound

$\mathrm{XRD}, \mathrm{X}$-ray diffraction. 